\title{
Reduction of the Uncertainties in the Hydrological Projections in Korean River Basins Using Dynamically Downscaled Climate Projections
}

\section{Liying Qiu}

The Hong Kong University of Science and Technology

Joeng-Bae Kim

Sejong University

\section{Seon-Ho Kim}

Sejong University

\section{Yeon-Woo Choi}

Massachusetts Institute of Technology

Eun-Soon Im ( $\nabla$ ceim@ust.hk)

The Hong Kong University of Science and Technology https://orcid.org/0000-0002-8953-7538

\section{Deg-Hyo Bae}

Sejong University

\section{Research Article}

Keywords: Uncertainty in hydrological projections, dynamical downscaling, bias correction, Korean river basin

Posted Date: October 18th, 2021

DOl: https://doi.org/10.21203/rs.3.rs-942462/v1

License: (9) This work is licensed under a Creative Commons Attribution 4.0 International License. Read Full License

Version of Record: A version of this preprint was published at Climate Dynamics on March 2nd, 2022. See the published version at https://doi.org/10.1007/s00382-022-06201-8. 


\section{Reduction of the uncertainties in the hydrological projections in Korean 2 river basins using dynamically downscaled climate projections}

4 Liying Qiu ${ }^{1+}$, Joeng-Bae Kim²+, Seon-Ho Kim², Yeon-Woo Choi ${ }^{3}$, Eun-Soon Im $^{* 1,4}$ and Deg$5 \quad \mathrm{Hyo} \mathrm{Bae}^{2}$

$7{ }^{1}$ Department of Civil and Environmental Engineering, The Hong Kong University of Science and Technology,

8 Hong Kong SAR, China

$9 \quad{ }^{2}$ Department of Civil and Environmental Engineering, Sejong University, Seoul, Korea

$10{ }^{3}$ Ralph M. Parsons Laboratory, Massachusetts Institute of Technology, Cambridge, MA, USA

$11{ }^{4}$ Division of Environment and Sustainability, The Hong Kong University of Science and Technology, Hong 12 Kong SAR, China

$13{ }^{+}$These authors contributed equally to this work

16 *Correspondence to: $\underline{\text { ceim } @ \text { ust.hk }}$

17 [Corresponding authors]

18 Prof. Eun-Soon Im

19 E-mail: ceim@ust.hk

20 Address: Academic Building 3594, The Hong Kong University of Science and Technology, Clear Water Bay,

21 Kowloon, Hong Kong, China.

\section{ORCID}

24 Liying Qiu (0000-0001-9944-4311)

25 Jeong-Bae Kim (0000-0002-6121-7751)

26 Seon-Ho Kim (0000-0002-1217-2075)

27 Yeon-Woo Choi (0000-0002-3400-6705)

28 Eun-Soon Im (0000-0002-8953-7538)

29 Deg-Hyo Bae (0000-0002-0429-1154) 
Abstract

31 How the added value of dynamically downscaled climate variables can be transferable to the hydrological 32 impact assessment has been a long standing issue. This study investigates the potential benefit of high33 resolution climate data locally tailored over South Korea in terms of the reduction of uncertainties in 34 hydrological projections. For this purpose, a large ensemble consisting of three Global Climate Model (GCM) projections and their downscaling products with different resolutions (i.e., 20 and $5 \mathrm{~km}$ ), and four bias correction (BC) methods is fed into a semi-distributed hydrological model (HM) customized over Korean river basins. The in-depth comparison among the 45 -members hydrological simulations proves that the added value of RCM would not be erased by the application of BC. While this study acknowledges the necessity of $\mathrm{BC}$ to remove the systematic bias in climate simulations, it is found that the high-resolution dynamical downscaling can significantly narrow the spread brought with different $\mathrm{BC}$ methods, thus reducing the uncertainty in the projected hydrological change. The projected streamflow changes for both the mean of wet season and the high flows indicate that there will be an intensified runoff, especially for the extremes, over South Korea under the warming. Altogether, this study provides a valuable exploration of uncertainty reduction in hydrological projections from the perspective of resolution effect of dynamical downscaling, which is meaningful for hydroclimate studies and climate change impact assessment.

\section{$47 \quad$ Keywords}

48 Uncertainty in hydrological projections, dynamical downscaling, bias correction, Korean river basin

\section{Declarations}

\section{$51 \quad$ Funding}

52 This study was carried out with the support of "Research Program for Agricultural Science \& Technology 53 Development (Project No. PJ014882)", National Institute of Agricultural Sciences, Rural Development 54 Administration, Republic of Korea. Kim JB, Kim S-H, and Bae D.-H. were supported by Korea 55 Environment Industry \& Technology Institute (KEITI) through Water Management Research

56 Program, funded by Korea Ministry of Environment(MOE) (130747).

\section{Conflicts of interest}

58 The authors declare that the research was conducted in the absence of any commercial or financial 59 relationships that could be construed as a potential conflict of interest.

\section{Availability of data and material}

61 The CMIP5 data is available from ESGF repository (https://esgf-node.llnl.gov/projects/cmip5/). Other data 62 that support the findings of this study are available from the corresponding author upon reasonable request.

\section{Code availability}

64 The authors used R packages "downscaleR" (version 3.1.0) and "MBC" (version 0.10-5) for BC, and VIC 65 hydrological model for shydrological simulation, which are all free online. 


\section{Introduction}

69 One of the most critical impacts of climate change that needs deep understanding and profound planning is the change in the Earth's hydrological cycle. It is expected that the river flows will witness substantial transitions affected by the changes in multiple processes under the global warming. For example, the exposure to flood hazards will continue to increase as the heavy rainfall increases under global warming on a local scale (Kundzewicz et al. 2014). Almost all of the physical processes included in the hydrological cycle, e.g., precipitation, evapotranspiration, infiltration, runoff, and routing, will be affected by the increasing temperature and relevant water vapor change, either directly or indirectly (Held and Soden 2006). Such changes in the water cycle should be carefully studied because they may impact the entire environment or even cause severe disasters. The reliable hydrological projections under global warming are thus urgently needed for the timely planning of water resource management and mitigation of the possible damages (Sun et al. 2017).

80 Currently, the hydrological projections are usually realized in a modeling chain consisting of climate models (CMs), bias corrections (BCs), and hydrological model (HMs) (Teutschbein and Seibert 2012; Muerth et al. 2013), which covers the numerical simulations of various physical processes and the statistical correction based on observed meteorological conditions. In this case, although HM is the last and direct tool for the streamflow simulation, the quality of hydrological projections is yet highly dependent on the reliability of the meteorological input into the HMs. The uncertainty sources of hydrological projections have been quantified in the previous studies for different regions around the world. These studies generally reach a similar conclusion that for most regions, CMs act as the leading source of uncertainty for the wet season or high flow projections (e.g., Aryal et al. 2019; Zhang et al. 2021), whereas HMs may contribute more to the uncertainty of dry season or low flow projections (e.g., Vetter et al. 2017; Lee et al. 2021). Also, the interactions among the uncertainty factors are non-negligible and may even play a larger role than the individual sources (Bosshard et al. 2013; Vetter et al. 2015; Zhang et al. 2021). For example, the impact of $\mathrm{BC}$ on runoff will increase with the bias of CMs (Muerth et al. 2013), because the correcting coefficient is scaled by the deviation of historical climate simulations from the observation. More importantly, considering the complicated and non-linear processes evolved in the climate system, the assumption of stationary bias for the present and future climate simulations used by BC (Teutschbein and Seibert 2012) is likely to distort the projected relative change if the correcting factor is too large.

97 To improve the reliability of meteorological input to the hydrological projections, one of the most popular 98 approaches is to downscale the coarse-resolution climate simulations from the Global Climate Models 99 (GCMs) by the Regional Climate Models (RCMs). Since the surface hydrological processes typically occur 100 on scales finer than GCMs, RCMs can help to reduce the resolution gap and improve the quality of modeled 101 meteorological conditions by resolving the small-scale processes. During the past decade, there have already 102 been considerable efforts to apply and evaluate the benefits of dynamical downscaling products in 103 hydrological impact assessments (Kotamarthi et al. 2021). However, the current typical grid size of 10-50 104 km (e.g., Giorgi and Gutowski 2015; Jacob et al. 2020) employed in RCMs still cannot meet the desirable 105 spatial scale and information quality required by HMs. For example, the bias in the estimation of rainfall106 driven flood can be largely attributed to the underestimation of daily precipitation variability and extreme 107 events in the climate simulations. To resolve such problems and reduce the subsequent uncertainty in 108 hydrological projections, the most straightforward and reliable way is to increase the resolution of RCMs 109 (Qiu et al. 2020), which can enhance the reliability of the regional climate projections through a better 110 representation of the complex topography and physical mechanisms.

111 On the other hand, although there is a growing consensus regarding the necessity of reliable meteorological 
112 input for HMs (Maraun et al. 2010), there are few explicit assessments of how the high-resolution RCMs 113 help to reduce the uncertainty in hydrological projections. Especially under the extensive use of BC 114 techniques, many studies are not aware of, or not clear about, how the quality of original climate simulations 115 affects the reliability of hydrological impact assessments. Quite a few hydrological projections are still using 116 GCM simulations processed only with simple interpolation and BC (e.g., Stefanidis et al. 2018; Zaman et al. 117 2018; Anjum et al. 2019; Haider et al. 2020), despite the apparent incompatibility in the scale of the CM and

118 HM. Even for those using the RCM products, they might also be uncertain about how dynamical downscaling 119 and BC are affecting the results (Maraun et al. 2010). As a post-processing tool for climate model output, BC 120 is useful but the application without good understanding of its relationship with the climate simulation may 121 lead to problematic conclusions. It is warned that BC may have limited ability to correct and downscale 122 variability, and it may even provide implausible climate change signals (Maraun et al. 2017). Thus, an 123 integrated assessment should be made regarding how dynamical downscaling aids in the uncertainty 124 reduction hydrological projection modeling chain, which is especially meaningful in this era of continuous 125 marching into high-resolution climate simulation.

126 In this study, we conduct a large ensemble of hydrological projections driven by long-term climate change 127 simulations over South Korea from three different resolutions, i.e., three GCMs and their dynamical 128 downscaling products in 20 and $5 \mathrm{~km}$. As a follow-up study of Qiu and $\operatorname{Im}(2021)^{1}$, this study aims to evaluate and explore how the demonstrated advantage of very-high-resolution (i.e., $5 \mathrm{~km}$ ) climate simulation benefits the hydrological studies. In this regard, we use four BC methods to process the climate projections of the three resolutions and feed the original and bias-corrected climate data into a designated HM for streamflow projections. Although previous studies have quantified the uncertainty contribution from $\mathrm{CM}, \mathrm{BC}$, and $\mathrm{HM}$, we focus on how the combination of very-high-resolution RCM simulations and different BC methods affect the hydrological projection output. The 5-km dynamical downscaling is not only the finest resolution longterm climate projections over this region so far, but more importantly, there have been few hydrological projections driven by RCM products at such a high resolution before despite the study area. Although the very-high-resolution dynamical downscaling has shown an added value over the coarse resolution highlighted by the improved reliability in the projected climate change features, this may seem "useless" to the end-users if no improvements can be seen in the hydrological projections that are run with bias-corrected climate data. Therefore, we adopt $\mathrm{BC}$ methods with different levels of complexity to provide a comprehensive comparative assessment for hydrological projections driven by the climate scenarios in different combinations of $\mathrm{CM}$ resolution and $\mathrm{BC}$ technique. It serves to provide straightforward information for the hydrological modeling community regarding the practical value of the high-resolution dynamical downscaling and the large ensemble of hydrological projections also adds valuable insight into the understanding of the regional water cycle change.

\section{Methodology and data}

\section{$147 \quad 2.1$ Experimental procedure and study area}

148 Fig. 1a presents the experimental framework of this study in three steps: climate simulation, statistical BC, 149 and hydrological simulation with HM. Three Coupled Model Intercomparison Project Phase 5 (CMIP5, 150 Taylor et al 2012) GCM projections under the RCP8.5 scenario and their downscaling products in $20 \mathrm{~km}$ and $1515 \mathrm{~km}$ are combined with different BC methods to constitute a 3 [CMIP5 models] $\times 3$ [resolutions] $\times(4+1)$ $152[\mathrm{BC}$ methods $]=45$-members ensemble of climate scenarios for driving hydrological simulations. The climate 153 and hydrological simulations both cover 30-yr periods for the reference (REF, 1976-2005) and the future

\footnotetext{
${ }^{1}$ Qiu L, Im E-S (2021) Added value of high resolution climate projections over South Korea on the scaling of precipitation with temperature. Environ Res Lett. Under Review
} 
(FUT, 2071-2100) over South Korea (Fig. 1b). The Korean Peninsula is a typical region needing highresolution climate modeling since its hydroclimate characteristics are strongly influenced by the varying geographic features with sharp topographical gradients encompassed by long coastlines. Also, it has been demonstrated the river flows of South Korea will witness substantial changes (Ryu et al. 2011; Jung et al. 2013; Seo et al. 2016; Ahn and Kim 2016; Lee et al. 2018a, 2021; Kim et al. 2020) given the condition that the regional climate has been projected to experience a non-trivial change in the future (Seo et al. 2013; Kim et al. 2018; Oh and Suh 2018). Though the simulations covering the whole country, we target over the Han River basin (HRB) and Nakdong River basin (NRB) for the streamflow analyses, which are the two largest river basins in South Korea taking up more than two-thirds of the area and a large portion of the population (Lee et al. 2019b). Meanwhile, to highlight the effect on uncertainty reduction from the climate scenarios, we mostly focus on the performance during the wet season (June to September, JJAS) and the high flows.

\subsection{Climate simulations}

Table 1 lists the 3 [CMIP5 models] $\times 3$ [resolutions] $=9$ climate projections under RCP8.5 scenario used in this study. The three CMIP5 models (i.e., CCSM4, NorESM1-M, and HadGEM2-ES, hereinafter as CCSM4, NorESM, and HadGEM2) were carefully selected to cover varying climate sensitivities and they all demonstrated reliable performances over East Asia. Then, a designated one-way double-nested system in the Weather Research and Forecasting model (WRF version 4.2, Skamarock et al. 2019) is used to downscale the three CMIP5 GCM projections into $20 \mathrm{~km}$ (hereinafter as WRF20) and $5 \mathrm{~km}$ (hereinafter as WRF05). Thus, for each CMIP5 model, we have climate simulations in the three resolutions (i.e., the original GCM, WRF20, and WRF05). The overall performance of the downscaling climate simulations and the added value of WRF05 were comprehensively evaluated in the previous studies (Qiu et al. 2020; Qiu and Im 2021).

175 For driving the hydrological simulations, the daily time series of maximum temperature (Tmax), minimum 176 temperature (Tmin), precipitation, and mean horizontal wind speed of the 9 climate simulations are needed. 177 To resolve the discrepancy among horizontal resolution in the climate simulations, the four meteorological 178 variables are first interpolated by distance-weighted average remapping onto the $0.125^{\circ}$ grid (i.e., the grid of 179 VIC simulation) before further post-processing.

\section{$180 \quad 2.3$ BC methods}

181 The principle of $\mathrm{BC}$ is to use observation as predictands for calibrating the simulated predictors. It can be used to correct the systematic bias in CM output, such as the overestimation of the occurrence of wet days and/or the underestimation of heavy precipitation (Maraun 2016). It is used to post-process either GCM or RCM data in almost all hydrological studies. Here, four BC methods are applied to three meteorological variables, i.e., daily Tmax, daily Tmin, and daily precipitation, for evaluating the effect of different combinations of climate simulations and $\mathrm{BC}$ methods on hydrological projections. The horizontal wind speed is not corrected because the $\mathrm{BC}$ of wind speed has little effect on the runoff projections (Haddeland et al. 2012). Instead, for both the hydrological simulation in REF and FUT, the same original wind speed data from REF simulations is used so that no consideration is given to its bias and the change under global warming.

190 The in-situ meteorological data used for correction is from 57 observation stations maintained by the Korean Meteorological Administration (KMA) during 1986-2005 (hereinafter as OBS). The station data is first interpolated onto the $0.125^{\circ}$ grid (i.e., the grid of VIC simulation) for consistency with the model data, and then the $\mathrm{BC}$ is applied on a grid-point base. A sliding window of three months central with each calendar month is used to consider the seasonality following Teutschbein and Seibert (2012) and Cannon (2018).

195 The four state-of-the-art BC methods used are namely Variance Scaling for temperature and Power

196 Transformation for precipitation (VAPT), Empirical Quantile Mapping (EQM), Quantile Delta Mapping 
(QDM), and Multivariate Bias Correction with the N-dimensional probability density function (MBCn). Specifically, VAPT, EQM, and QDM are applied by the R package "downscaleR" (version 3.1.0) (Bedia et al. 2020) and MBCn is applied by the R package "MBC" (version 0.10-5) (Cannon 2020). For the comparison, the raw climate simulation output without $\mathrm{BC}$ (hereinafter as RAW) is also used for hydrological simulation. Here, we include a brief introduction of the four $\mathrm{BC}$ methods below, but more detailed information can be reached from the relevant references.

VAPT is the combination of two relatively simple approaches for correcting temperature and precipitation, respectively, based on the monthly mean and variance (Chen and Dudhia 2001; Leander and Buishand 2007). Quantile Mapping $(\mathrm{QM})$ methods are the most popular BC technique and they follow the basic principle to make the Cumulative Distribution Function (CDF) of the modeled data equal to that of the observation after correction. EQM is one of the most extensively used QM methods and it uses the empirical CDF for the correction instead of assuming a parametric distribution (Teutschbein and Seibert 2012). QDM is a more advanced QM method because it tries to preserve the projected relative change in quantiles by removing and adding the future trend before and after QM (Cannon et al. 2015). Lastly, MBCn is a relatively "high-level" approach that uses an image processing technique to conduct multivariate-based BC. Unlike the other three methods that can correct only a single meteorological variable, it is applied to multiple variables at the same time by considering their joint dependence while also preserving the relative change pattern. Fig. 2 shows an illustrative example of the pairwise bivariate correlations for the observation and model output in this study. The correlation pattern in REF corrected by MBCn is more scattered, showing a higher similarity to OBS. The characteristics that the bias-corrected joint dependence in FUT depends on both the MBCn correcting algorithm calibrated for REF and the projected changes in the RAW may make MBCn better than the other three BC methods (Cannon 2018).

\subsection{Hydrological simulation}

To simulate the streamflow over South Korea, the bias-corrected and the RAW meteorological variables are fed into the Variable Infiltration Capacity (VIC) Macroscale Hydrologic Model (Liang et al. 1994; Hamman et al. 2018)) to generate the runoff. For simplicity, the corresponding experiments are called the "Model Resolution-Period_BC method". For example, CCSM $_{\text {WRF20-REF_VAPT }_{2}}$ is the 20-km WRF downscaling of CCSM4 for the REF period corrected by the VAPT method. Note that "ENS" stands for the ensemble mean of the output from the hydrological simulations driven by CCSM4, NorESM, and HadGEM2 (or ensemble mean of the hydrological output driven by their downscaling products), instead of using the ensemble-mean meteorological inputs to drive the hydrological simulations. And "ENSBC" is used at the subscript for representing the ensemble mean of the hydrological simulations driven by the same $\mathrm{CM}$ data but corrected by four different $\mathrm{BC}$ methods.

VIC is a large-scale, semi-distributed HM that has been applied widely for the analysis and assessments of climate change impacts on water resources by being coupled to different climate scenarios (e.g., Liang et al. 1994; Bae et al. 2015). A $0.125^{\circ}$ grid system covering South Korea except for the Jeju Island represented as 575 grid points is employed by VIC in this study (Fig. 1b). For hydrological simulations in the VIC, the geophysical datasets with the different spatial resolutions are collected from various sources and aggregated onto the $0.125^{\circ}$ grid. The 100 -m Digital elevation model (DEM) data is obtained from the Korean National Geographic Information Institute (NGII Korea). Soil data with a 1: 25,000 scale map is from Korea Rural Development Administration (RDA), and land cover data with a 1-km resolution is collected from the Water Resources Management Information System (WAMIS) of Korea. The VIC physics configuration follows Kim et al. (2020) that is set up specifically for this region and it has been proved to show optimal performance through sensitivity tests. Here, we perform an observational run for the validation of HM performance, in which precipitation observation during 1986-2005 maintained by the Korea Ministry of Environment (MOE) 
from WAMIS is additionally used for the forcing together with the KMA OBS data mentioned in Section 2.3. Fig. 3 shows the daily time series (left column) during REF of the simulated streamflow from the validation run and the measured streamflow. Since streamflow measurement is only available over specific sites (e.g., dam), the Chungju and Andong dams are selected respectively for the two target river basins. The in-situ measured daily inflow at the two dams were collected by WAMIS, and the simulation values are obtained by adding all the runoff values of VIC grids within the Chungju and Andong dam basins. Such a validation process has been widely used for the HM without horizontal routing module (Safeeq et al. 2014; Kim et al. 2020). The time series shows that the simulated streamflow well follows the measured dam inflows both in terms of the temporal variation and the runoff magnitude. The Nash-Sutcliffe efficiency (NSE) and percent bias (PBIAS) of the VIC model are 0.70/0.71 and -2.3\%/-3.55\% for Chungju/Andong dam basin respectively. These statistics demonstrate the ability of the VIC to capture the streamflow variability. Apart from the time series, Fig. 3 (right column) also provides a day-to-day validation based on the streamflow intensity. It shows that the HM better captures the high flows than the low flows that it may overestimate the flow less than 10 CMS. However, the simulation also tends to underestimate the high flows for the extreme tail, which may be due to the insufficient resolution in the OBS data, which has been smoothed due to the interpolation process, especially for the extremely heavy precipitation cases.

\section{$258 \quad 3$ Result}

\section{$259 \quad 3.1$ The effect of multiple BC methods on precipitation and temperature}

Before the streamflow projections, we first have a look at the precipitation and temperature in different combinations of climate simulations and BC methods. Fig. 4 presents the spatial pattern of the climatological

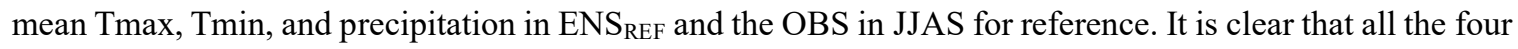
$\mathrm{BC}$ methods tend to reduce the bias in the climate simulations, regardless of how large the bias in the raw output is (e.g., precipitation in ENS $\mathrm{GCM}_{\mathrm{GCF}_{-} \mathrm{RAW}}$ ). Although slight differences exist among different BC methods, all of them show similarly good performance in terms of the seasonal mean, which is not surprising because $\mathrm{BC}$ methods are usually well designed for calibrating the monthly mean.

Then, following Cannon et al. (2015) and Seo et al. (2019), several Expert Team on Climate Change Detection and Indices (ETCCDI) indices (Zhang et al. 2011) are used for evaluating the performance of the BC methods. Seo et al. (2019) suggested that 7 ETCCDI indices together with the annual mean can be used as the representative meteorological indices for regional hydrologic impact studies. Here, we exclude those indices more related with the dry season or low flows and additionally include two precipitation indices. Altogether, 6 ETCCDI indices (Table 2) are calculated from all the 45 climate scenarios on a grid-point base. These indices cover both those for the extremes (e.g., Rxlday) and those for the annual mean/accumulation (e.g., SDII). Also, we include the JJAS mean of precipitation, Tmax, and Tmin instead of the annual mean in the evaluation, thus the 9 indices altogether can give a comprehensive assessment of the $\mathrm{BC}$ methods regarding the climate indices for hydrologic impact studies during the wet season.

The distributions of the 9 indices during REF from the model are evaluated against those from OBS using Kolmogorov-Smirnov (K-S) test at a 1\% significance level. A detailed technical explanation can be found in Cannon et al. (2015). Fig. 5 shows the proportion of grid points passing local K-S diagnostic tests for each index in each climate scenario, with warm colors standing for a higher proportion and thus better performance. The test result indicates a significant bias in the simulated distribution of the indices in RAW climate simulations. With the downscaling of increasing resolution (GCM-WRF20-WRF05), the bias reduces but still exists. BC helps to significantly improve the modeled distribution that the portion of grid points passing K-S exceeds $90 \%$ for most indices, except for CWD and SDII, which demonstrates the necessity of BC as a pre-processing tool for hydrological simulations. Also, for TN90p in NorESM $\mathrm{GCM}_{\mathrm{GEF}}$, it seems that BC cannot improve its annual distribution. Comparatively, despite the resolution of the models, the performance 
of $\mathrm{BC}$ methods can be roughly ranked as $\mathrm{MBCn}>\mathrm{QDM}>\mathrm{EQM}>\mathrm{VAPT}$, which generally corresponds with their degree of complexity and the computation cost. On the other hand, although $\mathrm{BC}$ can significantly reduce the bias in the RAW, it does not mean that the quality of the RAW climate simulations is not meaningful. Instead, even after BC, WRF05 still overweighs WRF20 in the K-S test, not to mention the original GCM. It indicates that the added value of high-resolution RCM would not be erased under the use of BC. Instead, the hybrid of WRF05 with MBCn, i.e., the best-performing dynamical downscaling with best-performing BC approach, yields a pass-portion of over $90 \%$ for all the indices including CWD, SDII, and TN90p for NorESM. While the bias-corrected result of the climatological mean seems to be independent of the quality of the RAW simulation, which is also a common skepticism about the necessity of dynamical downscaling (Lee et al. 2018b), this result proves that the quality of RAW still affects the extreme statistics even after BC. It is because that if the deviation of the original model simulation is prominent from the observation, the correction factors will also be large, potentially destructing the distribution of extremes that are often nonlinear to the climatological mean.

Moving to how the $\mathrm{BC}$ affects the projected change in precipitation and temperature, Fig. 6 shows the relative change of the climatological mean in JJAS. Although all the BC methods retain the change signs from the RAW, the discrepancy between the relative change in the bias-corrected products and that in the RAW varies with the CM resolution. It is within only $\pm 3 \%$ for WRF05, but that in the GCMs is much larger. Especially, the EQM-corrected changes in Tmax and Tmin for $\mathrm{ENS}_{\mathrm{GCM}}$ are much higher than the others; and the VAPTand EQM- corrected changes in precipitation also show more than $9 \%$ deviation from RAW in this case. Here, VAPT and EQM, compared to QDM and MBCn, do not give consideration to preserving the change trend during the correction processes. While this will not significantly affect the result of the high-resolution downscaled climate variables, it can lead to a large deviation from the RAW in the coarse resolution run given its large bias in the original climate simulations.

For zooming into the difference of projected change of the four BC methods, distributions over South Korea of the projected relative changes in the mean Tmax, Tmin, precipitation, and Rx5day as a representative of extreme precipitation, are displayed in Fig. 7. The black is drawn from the RAW, while the colored boxes are from the bias-corrected distributions. It shows that in the coarse resolution, the spatial variation is relatively smaller than in the high resolution, especially for precipitation and its extreme. $\mathrm{BC}$ can increase the spatial variability for all the simulations, but the resulted distributions from different $\mathrm{BC}$ methods also show differences. Among the four BC techniques applied, the delta method is adopted in QDM and MBCn that it may help them to preserve the change trend across different quantiles by design. EQM and VAPT, on the other, show large positive outliers compared to the RAW, which is also shown in Cannon et al. (2015). Here, in the $\mathrm{ENS}_{\mathrm{GCM}}$, the changes in $\mathrm{EQM}$-corrected mean Tmax and Tmin are larger than those corrected by other methods, and the changes in mean precipitation and Rx5day also show a large spread when corrected with different $\mathrm{BC}$ methods. For example, for Rx5day, the median in $\mathrm{ENS}_{\mathrm{GCM}_{-} \mathrm{VAPT}}$ is around $10 \%$ higher than $\mathrm{ENS}_{\mathrm{GCM} \_\mathrm{MBCn}}$. Comparatively, such a difference becomes much smaller as the resolution increases with downscaling. In ENS ${ }_{W R F 05}$, the larger change for EQM-corrected temperatures becomes smaller; and more importantly, it shows a primarily similar distribution for the precipitation change corrected by the four $\mathrm{BC}$ methods.

As a whole, $\mathrm{BC}$ shows remarkable performance in reducing the bias of the $\mathrm{CM}$ simulations, both for the mean and the extremes. Considering both the REF and FUT periods, QDM and MBCn outweigh VAPT and $\mathrm{EQM}$, while $\mathrm{MBCn}$ also shows unique privilege in additionally preserving inter-dependence among the corrected variable. However, the results across different climate simulations corrected by different $\mathrm{BC}$ methods prove that the added value of dynamical downscaling, including that of increasing resolution, still exists even after applying BC. The best combination of "CM-BC" evaluated here is "WRF05-MBCn". 


\subsection{Reducing the uncertainty in historical streamflow simulation}

333 In this section, we turn our focus onto the simulated streamflow for the REF period driven by the modeled meteorological variables, using the OBS-driven VIC simulation as the reference for validation. First, the analysis begins with the climatological monthly total runoff over the two basins (Fig. 8). The shaded area is from the OBS run; the black dashed lines mark the hydrological simulations driven by RAW and the colored lines delegate those driven by the bias-corrected meteorological conditions. Not surprisingly, there is little difference brought by different $\mathrm{BC}$ methods on the monthly time scale, which is consistent with the finding in Section 3.1. Also, compared to the RAW, BC improves the simulated runoff for all the models and resolutions. On the other hand, discrepancies among the CMIP5 models and the CM resolutions can be found. All the three original GCMs underestimate the peaks of streamflow in the wet season for the two basins. Although BC helps reduce such biases, the bias is still found especially for CCSM4 $4_{\mathrm{GCM}-\mathrm{REF}}$ over HRB and HadGEM2 $2_{\mathrm{GCM}-\mathrm{REF}}$ over NRB. The $\mathrm{BC}$ procedure that the correcting coefficient is obtained from a 90 -day window centered for individual months may explain the bias in the annual cycle. If the bias in the original climate simulation is too large, then the effect of the 90-day window will also be noticeable on the monthly statistics, though it may not be obvious when considering the seasonal mean. Comparatively, the downscaling with WRF improves the simulated annual cycle so that the simulated runoff after $\mathrm{BC}$ is much closer to the OBS. Here, the performances of WRF20 and WRF05 with BC are similar, which is reasonable since WRF20 has also been proved to perform well for the climatological monthly statistics in the previous study (Qiu et al. 2020). Fig. 8 also indicates a clear annual phase of the streamflow over South Korea. While the hydrological simulations driven by bias-corrected meteorological conditions can generally capture the entire annual cycle indicated in the OBS run, this study mainly focuses on the "wet season" defined as June to September that is a period with higher runoff.

Fig. 9a presents the mean for the wet season from $\mathrm{ENS}_{\mathrm{GCM}}, \mathrm{ENS}_{\mathrm{WRF} 20}$, and $\mathrm{ENS}_{\mathrm{WRF} 05}$ to evaluate the spatial patterns of the simulated runoff. The result shows that more extensive runoff is found for the HRB than the $\mathrm{NRB}$, and the NRB shows higher runoff on the south than the north. Such spatial characteristics are missed in $\mathrm{ENS}_{\mathrm{GCM}-\mathrm{REF} \_\mathrm{RAW}}$, accompanied by a significant underestimation in the magnitude. Downscaling much

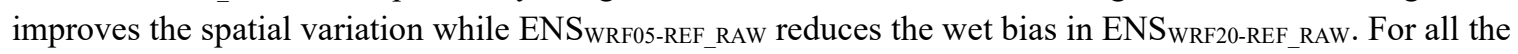
resolutions, BC significantly helps improve the simulated runoff. It reduces the bias in the runoff magnitude and improves the spatial distribution, which results in the highly similar patterns of the wet season mean runoff despite the $\mathrm{BC}$ methods used and the original climate simulation resolution.

For the mean of the annual maximum daily streamflow (AMDS), which is one of the indices for representing

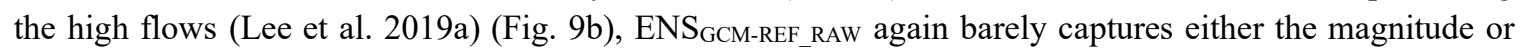
spatial distribution. The downscaling effectively demonstrates the effect of resolution in improving the reproduction of spatial variability, but it also inherits the problem of overestimation from the precipitation representation (Qiu and Im 2021). However, as mentioned in Section 2.4, it should also be noted that the hydrological simulation driven by interpolated station data (i.e., the OBS run) may have the problem of underestimated high flow, especially for the extremely heavy case. The application of BC, while greatly improving the performance of $\mathrm{ENS}_{\mathrm{GCM}-\mathrm{REF}}$ and also reducing the overestimation in NRB for ENS $\mathrm{WRF}_{\mathrm{WR}-\mathrm{REF}}$ and ENS ${ }_{\text {WRF05-REF, }}$ seems to "over-correct" the high flow for HRB in the hydrological simulations driven by downscaled products. The high flows in HRB from the simulations with BC show a larger discrepancy from OBS than those with RAW. This may be due to the fact that the BC coefficients for precipitation in WRF20 and WRF05 are primarily scaled by the majority of the distribution. That is, the correction coefficient is made to be negative to reduce the overestimation. However, for the very extreme cases represented by AMDS that are actually not overestimated in the RAW, the negative correction coefficients, on the contrary, distort the distribution of extremes. 
In all, the above analyses show the benefits and necessity of BC for post-processing either GCM or RCM output before applying them to the HMs. It is useful in improving the simulated streamflow especially when there is a large bias in the original climate simulations. However, the BC may cause the problem in the very extreme values (e.g., AMDS) when the signal of their bias is different from that in the majority of the 381 distribution.

\section{$382 \quad 3.3$ Reducing the uncertainty in future streamflow projection}

383 For the streamflow projection for the future, Fig. 10 presents the spatial pattern of the relative change in the runoff during wet season from the hydrological simulations driven by RAW climate simulations and the ensemble mean of the hydrological simulations driven by same CM data corrected by four different $\mathrm{BC}$ methods (i.e., ENSBC). The signal of the intensified streamflow occupies a large area in the target basins, but disagreement among the models can still be seen where uncertainty has been found in the projected precipitation change, mainly in the middle of Korean Peninsula (Qiu and Im 2021). The simulated change of streamflow follows a similar spatial pattern with precipitation for all the models in all the resolutions, which is understandable because precipitation takes up the major contribution to wet season river runoffs. The intermodel uncertainty is highly subject to the levels of warming in the corresponding GCMs, that the decreasing signals appear over the middle and south part of the country under a low warming level (i.e., CCSM4 in this study). Similar precipitation change pattern were projected in previous downscaling studies with other GCMs and RCMs (Kim et al. 2018; Oh and Suh 2018), and such uncertainty in precipitation projection is then reflected on the streamflow projection.

On the other hand, for the comparison between RAW and ENSBC, the simulated runoff from bias-corrected meteorological conditions shows a qualitatively similar pattern with RAW in terms of the change signal and spatial distribution. However, the coarse resolution shows quite a large difference in the projected change magnitude with and without BC. For example, the relative change in NorESM GCM_ENSBC $_{\text {EN }}$ is more than two

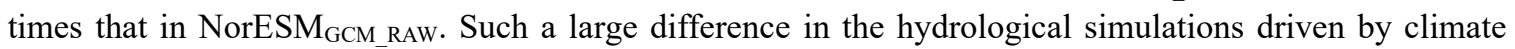
conditions with and without $\mathrm{BC}$ is a non-negligible uncertainty in the understanding of the projected change.

Compared to the seasonal mean, the high flows may need more of our attention due to their severe impacts on human society. Thus, to have a deeper investigation of how the resolution of dynamical downscaling and statistical BC affect the streamflow projections, Fig. 11 presents the relative change of two high flow indexes, i.e., AMDS and Q95 (the daily streamflow exceeded $95 \%$ of the time throughout the year), from all the hydrological simulations. Note that the high flow indexes in Fig. 11 are derived on a basin basis rather than a grid basis. That is, the daily streamflow of each grid point is summed up over the basin first before calculating the indexes. The black is from the RAW and different colors are for different BC methods. Similar to the mean of wet season, the result shows that all the simulations project the high flow to increase. Also, the high flow may likely witness a considerably larger magnitude of increase than the seasonal mean, which is consistent with the general finding that the heavy precipitation will increase more intensely than the average.

However, one thing that should be stressed is that the discrepancy in the projected change among the $\mathrm{BC}$ methods varies with the climate simulation resolution. There is a distinctly smaller range of spread among the different BC methods for WRF05-driven hydrological simulations than those driven with WRF20 and $\mathrm{GCM}$ in the projected increase. For example, the NorESM $\mathrm{GCM}_{\mathrm{GC}}$ with different $\mathrm{BC}$ methods shows an increasing rate from $60 \%$ to $110 \%$ for the AMDS over NRB, while that range for NorESM $\mathrm{WRF}_{\mathrm{W} 5}$ is less than $3 \%$. The large spread brought with different BC methods in the GCM-driven hydrological simulations can be significantly reduced by the downscaling with increasing resolution, which can be seen as the reduction of uncertainty in the projected result. Especially for WRF05, not only is the deviation range narrowed among different $\mathrm{BC}$ methods, the projected high flow change driven by meteorological conditions with and without 
$\mathrm{BC}$ is also relatively small. This result is very meaningful because if the difference brought with $\mathrm{BC}$ methods can lead to such large uncertainty in the result, then it is hard to tell if the projected streamflow change is reliable or not. Especially, hydrological projections normally just use one or two BC methods to correct the meteorological variables. It is very likely that they simply rely on the bias-corrected result during the historical period but ignore such huge uncertainty in the projected streamflow change.

\section{Discussion and summary}

This study investigates the effect of very-high-resolution dynamical downscaling in the application of hydrological impact assessment. Although the benefits of RCM have been elaborated by comparing against observation and exploring the physical mechanisms behind it in many previous studies, the direct evaluation in hydrological implication may be more straightforward and meaningful for the end users (e.g., hydrological modeling community). In this regard, we use the multi-model, multi-resolution climate simulation ensemble to feed HM in combination with different $\mathrm{BC}$ methods to project the streamflow change in South Korea at the end of the 21st century. Three CMIP5 GCMs are downscaled into WRF20 and WRF05, and four BC methods covering simple-to-complicated approaches are used for post-processing the climate data to facilitate a comprehensive assessment.

The results from the original climate simulations and the hydrological simulations driven by RAW show that high-resolution dynamical downscaling can significantly improve the simulated meteorological and hydrological variables, while we also acknowledge that $\mathrm{BC}$ plays an indispensable role in reducing the systematic bias in CM. However, although the bias-corrected product seems similar for the simulated seasonal mean during the REF period, this does not mean that BC would erase the added value of highresolution RCM. From the one side, WRF05 still preserves a better performance than GCM and WRF20 after $\mathrm{BC}$ for the reproduction of spatial variability and extreme indices in the REF period. On the other hand, more importantly, the higher resolution downscaling can help reduce the uncertainty of the projected change brought by $\mathrm{BC}$.

For all the hydrological simulations considered, they agree with an increase in wet season streamflow and especially the high flows over the targeted basins for the future. However, discrepancies can be found among the hydrological simulations driven by different GCMs, different resolutions of RCM, and the climate simulation post-processed by different BC methods. Although the projected streamflow change generally follows the pattern of change in the simulated precipitation, it is found that the improved representation in WRF05 can help reduce the uncertainty brought by different BC methods in the projected streamflow change, particularly for the high flows. The non-negligible bias in the coarse-resolution climate simulations during the REF period, on the contrary, leads to the large correcting coefficients that are very likely to induce considerable difference among different $\mathrm{BC}$ methods for the projected change, which greatly impairs the reliability of the subsequent hydrological projections.

466

Currently, there are more and more high-resolution dynamically-downscaled climate products available, but there is still a long way to go for advertising their value to the end-users. Thus, the added value assessment of high resolution RCM should not be limited to region-specific climate features; a straightforward comparison for the hydrological simulations driven by different CM products may enable a more convincing evaluation from the perspective of impact assessment application. Note that this study does not neglect the effect of the statistical post-processing tools. On the other hand, we emphasize that the high resolution dynamical downscaling can reduce the uncertainty in $\mathrm{BC}$ while acknowledging the effect of $\mathrm{BC}$ on removing the systematic bias in climate simulations. Some studies stick to using GCMs for driving HM because they argue that $\mathrm{BC}$ is enough for reducing the bias seen in the reference period. However, this study points out that although the bias-corrected product seems "excellent" during the reference period, there can be a significant difference in the projected change using different BC methods. While previous study also pointed 
out the impact of BC on runoff will increase with the bias of CMs (Muerth et al. 2013), this study is the first trial from the perspective of the large ensemble projections to assess the impact the very-high-resolution in dynamical downscaling to the modeling chain of CM-BC-HM. Although we do not explicitly quantify the uncertainty contribution from each source, which is not the focus of this study, we clearly demonstrate that the high-resolution RCM can narrow the spread from different BC methods and thus reduce the uncertainty in the hydrological projections.

Altogether, the comparative assessment provides valuable information for understanding the hydrological change under global warming of this region and for assessing the resolution effect in the model chain of climatic - hydrological simulations. Especially, the added value found in the hydrological application is not common, and it offers an added value in a wide-ranging context and thus can serve to advance the understanding and utilization of climate downscaling. Also, although some of the projected changes are consistent with the findings in previous studies, the generated hydroclimate dataset still provides an unprecedented multi-model, high-resolution ensemble of hydrological projections for this region. It is meaningful for the scientific and end-user communities for the process understanding and impact assessment.

For further study, more HMs should be considered for a better understanding of the uncertainty stemming In particular, the HM applied, VIC, is a semi-distributed model. Therefore, it is necessary to evaluate and compare the uncertainty from HMs with a different structure such as lumped models or fully-distributed models. Also, only one resolution, $12.5 \mathrm{~km}$, is applied for the HM. For thoroughly examining the effect of high resolution dynamical downscaling, a larger ensemble of HM with different resolutions may help gain a clearer idea of the appropriate resolution necessary for a reasonable hydrological climate change impact assessment.

\section{Reference}

Ahn SR, Kim SJ (2016) Assessment of climate change impacts on the future hydrologic cycle of the Han River Basin in South Korea using a grid-based distributed model. Irrig Drain 65:11-21. https://doi.org/10.1002/ird.1963

Anjum MN, Ding Y, Shangguan D (2019) Simulation of the projected climate change impacts on the river flow regimes under CMIP5 RCP scenarios in the westerlies dominated belt, northern Pakistan. Atmos Res 227:233-248. https://doi.org/10.1016/j.atmosres.2019.05.017

Aryal A, Shrestha S, Babel MS (2019) Quantifying the sources of uncertainty in an ensemble of hydrological climate-impact projections. Theor Appl Climatol 135:193-209. https://doi.org/10.1007/s00704-0172359-3

Bae D-H, Koike T, Awan JA, Lee M-H, Shon K-He (2015) Climate change impact assessment on water resources and susceptible zones identification in the Asian Monsoon region. Water Resour Manag 29:5377-5393. https://doi.org/10.1007/s11269-015-1124-6

Bedia J, Baño-Medina J, Legasa MN, Iturbide M, Manzanas R, Herrera S, Casanueva A, San-Martin D, Cofino AS, Gutierrez M (2020) Statistical downscaling with the "downscaleR" package (v3.1.0): contribution to the VALUE intercomparison experiment. Geosci Model Dev 13:1711-1735. https://doi.org/10.5194/gmd-13-1711-2020

Bosshard T, Carambia M, Goergen K, Kotlarski S, Krahe P, Zappa M, Schär C (2013) Quantifying uncertainty sources in an ensemble of hydrological climate-impact projections. Water Resour Res 49:1523-1536. https://doi.org/10.1029/2011WR011533

Cannon AJ (2018) Multivariate quantile mapping bias correction: an N-dimensional probability density function transform for climate model simulations of multiple variables. Clim Dyn 50:31-49. https://doi.org/10.1007/s00382-017-3580-6

Cannon AJ (2020) R Package 'MBC': Multivariate Bias Correction of Climate Model Outputs

Cannon AJ, Sobie SR, Murdock TQ (2015) Bias correction of GCM precipitation by Quantile Mapping: How well do methods preserve changes in quantiles and extremes? J Clim 28:6938-6959. 
https://doi.org/10.1175/JCLI-D-14-00754.1

Chen F, Dudhia J (2001) Coupling an advanced land surface - hydrology model with the Penn State - NCAR MM5 Modeling System. Part I : Model implementation and sensitivity. Mon Weather Rev 129:569585. https://doi.org/10.1175/1520-0493(2001)129<0569:caalsh $>2.0 . c o ; 2$

Giorgi F, Gutowski WJ (2015) Regional dynamical downscaling and the CORDEX Initiative. Annu Rev Environ Resour 40:467-490. https://doi.org/10.1146/annurev-environ-102014-021217

Haddeland I, Heinke J, Voß F, Eisner S, Chen C, Hagemann S, Ludwig F (2012) Effects of climate model radiation, humidity and wind estimates on hydrological simulations. Hydrol Earth Syst Sci 16:305-318. https://doi.org/10.5194/hess-16-305-2012

Haider H, Zaman M, Liu S, Saifullah M, Usman M, Chauhdary JN, Anjum MN, Waseem M (2020) Appraisal of climate change and its impact on water resources of Pakistan: A case study of Mangla Watershed. Atmosphere 11:1071. https://doi.org/10.3390/atmos11101071

Hamman JJ, Nijssen B, Bohn TJ, Gergel DR, Mao Y (2018) The Variable Infiltration Capacity model version 5 (VIC-5): infrastructure improvements for new applications and reproducibility. Geosci Model Dev 11:3481-3496. https://doi.org/10.5194/gmd-11-3481-2018

Held IM, Soden BJ (2006) Robust responses of the hydrological cycle to global warming. J Clim 19:56865699. https://doi.org/10.1175/JCLI3990.1

Jacob D, Teichmann C, Sobolowski S, et al (2020) Regional climate downscaling over Europe: Perspectives from the EURO-CORDEX community. Reg Environ Change 20:51. https://doi.org/10.1007/s10113020-01606-9

Jung IW, Bae DH, Lee BJ (2013) Possible change in Korean streamflow seasonality based on multi-model climate projections. Hydrol Processes 27:1033-1045. https://doi.org/10.1002/hyp.9215

Kim G, Cha DH, Park C, et al (2018) Future changes in extreme precipitation indices over Korea. Int J Climatol 38:e862-e874. https://doi.org/10.1002/joc.5414

Kim J-B, Im E-S, Bae D-H (2020) Intensified hydroclimatic regime in Korean basins under 1.5 and $2{ }^{\circ} \mathrm{C}$ global warming. Int J Climatol 40:1965-1978. https://doi.org/10.1002/joc.6311

Kotamarthi R, Hayhoe K, Mearns L, Wuebbles D, Jacobs J, Jurado J (2021) Added value of Downscaling. In: Downscaling techniques for high-resolution climate projections: From global change to local impacts. Cambridge University Press, Cambridge, pp102-120

Kundzewicz ZW, Kanae S, Seneviratne SI, et al (2014) Flood risk and climate change: global and regional perspectives. Hydrol Sci J 59:1-28. https://doi.org/10.1080/02626667.2013.857411

Leander R, Buishand TA (2007) Resampling of regional climate model output for the simulation of extreme river flows. J Hydrol 332:487-496. https://doi.org/10.1016/j.jhydrol.2006.08.006

Lee J-H, Park S-Y, Kim J-S, Sur C, Chen J (2018a) Extreme drought hotspot analysis for adaptation to a changing climate: Assessment of applicability to the five major river basins of the Korean Peninsula. Int J Climatol 38:4025-4032. https://doi.org/10.1002/joc.5532

Lee M-H, Bae D-H, Im E-S (2019a) Effect of the horizontal resolution of climate simulations on the hydrological representation of extreme low and high flows. Water Resour Manag 33:4653-4666. https://doi.org/10.1007/s11269-019-02359-9

Lee M-H, Lu M, Im E-S, Bae D-H (2018b) Added value of dynamical downscaling for hydrological projections in the Chungju Basin, Korea. Int J Climatol 39:516-531. https://doi.org/10.1002/joc.5825

Lee M-H, Qiu L, Ha S, Im E-S, Bae D-H (2021) Future projection of low flows in the Chungju basin, Korea and their uncertainty decomposition. Int J Climatol 1-18. https://doi.org/10.1002/joc.7237

Lee M-H, Im E-S, Bae D-H (2019b) A comparative assessment of climate change impacts on drought over Korea based on multiple climate projections and multiple drought indices. Clim Dyn 53:389-404. https://doi.org/10.1007/s00382-018-4588-2

Liang X, Lettenmaier DP, Wood EF, Burges SJ (1994) A Simple hydrologically based model of land surface water and energy fluxes for general circulation models. J Geophys Res 99:14415-14428. https://doi.org/10.1029/94JD00483

Maraun D (2016) Bias correcting climate change simulations - a critical review. Curr Clim Change Rep 2:211-220. https://doi.org/10.1007/s40641-016-0050-x

Maraun D, Shepherd TG, Widmann M, et al (2017) Towards process-informed bias correction of climate change simulations. Nat Clim Change 7:764-773. https://doi.org/10.1038/nclimate3418

Maraun D, Wetterhall F, Chandler RE, et al (2010) Precipitation downscaling under climate change: Recent 
developments to bridge the gap between dynamical models and the end user. Rev Geophys 48:RG3003. https://doi.org/10.1029/2009RG000314

Muerth MJ, Gauvin St-Denis B, Ricard S, Velázquez JA, Schmid J, Minville M, Caya D, Chaumont D, Ludwig R, Turcotte R (2013) On the need for bias correction in regional climate scenarios to assess climate change impacts on river runoff. Hydrol Earth Syst Sci 17:1189-1204. https://doi.org/10.5194/hess-17-1189-2013

Oh SG, Suh MS (2018) Changes in seasonal and diurnal precipitation types during summer over South Korea in the late twenty-first century (2081-2100) projected by the RegCM4.0 based on four RCP scenarios. Clim Dyn 51:3041-3060. https://doi.org/10.1007/s00382-017-4063-5

Qiu L, Im E-S, Hur J, Shim K-M (2020) Added value of very high resolution climate simulations over South Korea using WRF modeling system. Clim Dyn 54:173-189. https://doi.org/10.1007/s00382-01904992-x

Ryu JH, Lee JH, Jeong S, Park SK, Han K (2011) The impacts of climate change on local hydrology and low flow frequency in the Geum River Basin, Korea. Hydrol Processes 25:3437-3447. https://doi.org/10.1002/hyp.8072

Safeeq M, Mauger GS, Grant GE, Arismendi I, Hamlet AF, Lee S-Y (2014) Comparing large-scale hydrological model predictions with observed streamflow in the Pacific Northwest: Effects of climate and groundwater. J Hydrometeorol 15:2501-2521. https://doi.org/10.1175/JHM-D-13-0198.1

Seo K-H, Ok J, Son J-H, Cha D-H (2013) Assessing future changes in the East Asian Summer Monsoon using CMIP5 coupled models. J Clim 26:7662-7675. https://doi.org/10.1175/JCLI-D-12-00694.1

Seo SB, Kim Y-O, Kim Y, Eum H-I (2019) Selecting climate change scenarios for regional hydrologic impact studies based on climate extremes indices. Clim Dyn 52:1595-1611. https://doi.org/10.1007/s00382018-4210-7

Seo SB, Sinha T, Mahinthakumar G, Sankarasubramanian A, Kumar M (2016) Identification of dominant source of errors in developing streamflow and groundwater projections under near-term climate change. J Geophy Res Atmos 121:7652-7672. https://doi.org/10.1002/2016JD025138

Skamarock WC, Klemp JB, Dudhia J, et al (2021) A description of the Advanced Research WRF Model Version 4.3. https://doi.org/10.5065/1dfh-6p97

Stefanidis K, Panagopoulos Y, Mimikou M (2018) Response of a multi-stressed Mediterranean river to future climate and socio-economic scenarios. Sci Total Environ 627:756-769. https://doi.org/10.1016/j.scitotenv.2018.01.282

Sun W, Wang Y, Wang G, Cui X, Yu J, Zuo D, Xu Z (2017) Physically based distributed hydrological model calibration based on a short period of streamflow data: Case studies in four Chinese basins. Hydrol Earth Syst Sci 21:251-265. https://doi.org/10.5194/hess-21-251-2017

Taylor KE, Stouffer RJ, Meehl GA (2012) An overview of CMIP5 and the experiment design. Bull Am Meteorol Soc 93:485-498. https://doi.org/10.1175/BAMS-D-11-00094.1

Teutschbein C, Seibert J (2012) Bias correction of regional climate model simulations for hydrological climate-change impact studies: Review and evaluation of different methods. J Hydrol 456-457:12-29. https://doi.org/10.1016/j.jhydrol.2012.05.052

Vetter T, Huang S, Aich V, Yang T, Wang X, Krysanova V, Hattermann F (2015) Multi-model climate impact assessment and intercomparison for three large-scale river basins on three continents. Earth Syst Dyn 6:17-43. https://doi.org/10.5194/esd-6-17-2015

Vetter T, Reinhardt J, Flörke M, et al (2017) Evaluation of sources of uncertainty in projected hydrological changes under climate change in 12 large-scale river basins. Clim Change 141:419-433. https://doi.org/10.1007/s10584-016-1794-y

Zaman M, Naveed Anjum M, Usman M, Ahmad I, Saifullah M, Yuan S, Liu S (2018) Enumerating the effects of climate change on water resources using GCM scenarios at the Xin'anjiang Watershed, China. Water 10: 1296. https://doi.org/10.3390/w10101296

Zhang L, Yuan F, Wang B, et al (2021) Quantifying uncertainty sources in extreme flow projections for three watersheds with different climate features in China. Atmos Res 249:105331. https://doi.org/10.1016/j.atmosres.2020.105331

Zhang X, Alexander L, Hegerl GC, Jones P, Tank AK, Peterson TC, Trewin B, Zsiers FW (2011) Indices for monitoring changes in extremes based on daily temperature and precipitation data. WIREs Clim Change 2:851-870. https://doi.org/https://doi.org/10.1002/wcc.147 


\section{Figures}

(a) Experimental framework

(b) Study area

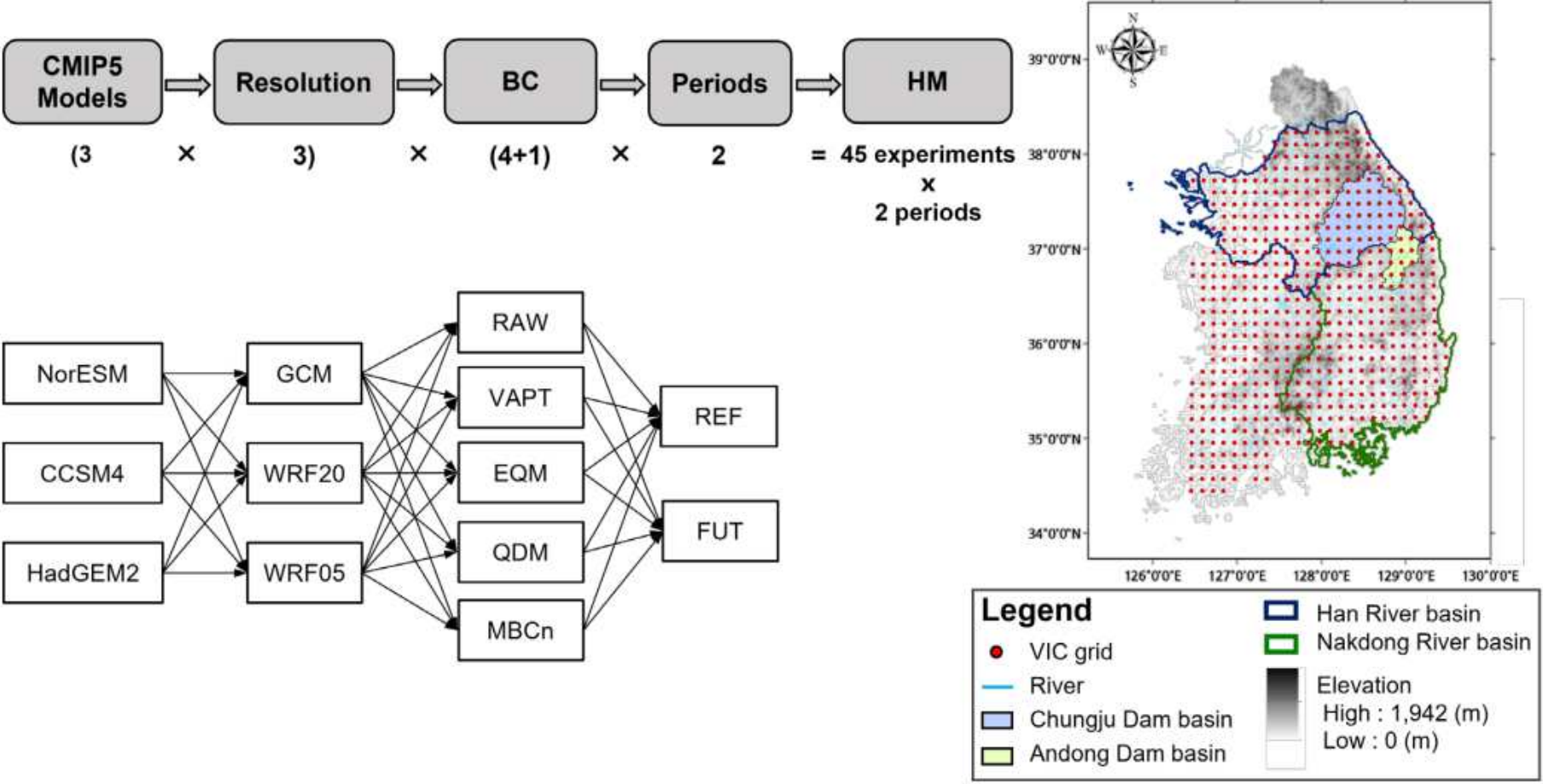

Figure 1

(a) Experimental framework that shows the combinations of different CMIP5 models, CM resolutions, and BC methods; (b) Elevation map of the study area derived from the 30-m Digital Elevation Map (unit: $\mathrm{m}$ ) and the grid system employed by the VIC model in $0.125^{\circ}$ grid over South Korea. The tributaries of the main rivers are marked by the light blue lines. This study focuses on Han River basin (HRB) and Nakdong River basin (NRB) outlined by the thick blue and green lines, respectively. The Chungju and Andong dam basins (shaded area) are selected for validation for HRB and NRB respectively. 


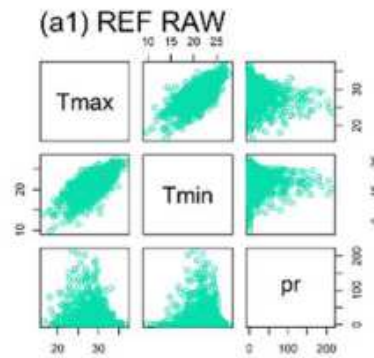

(a2) FUT RAW

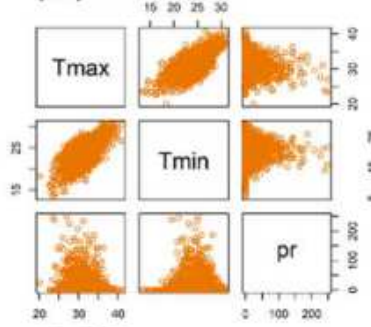

(b1) REF VAPT

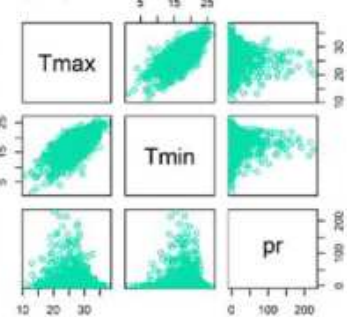

(b2) FUT VAPT
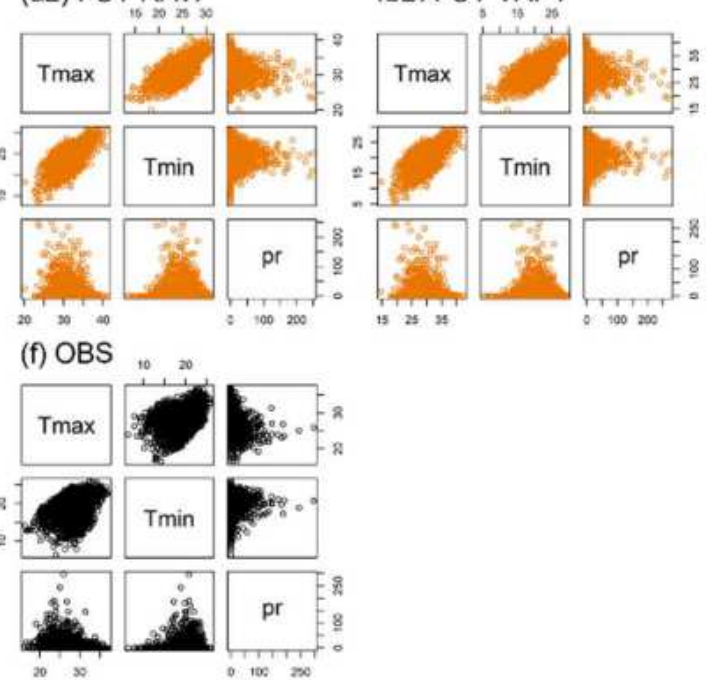

(c1) REF EQM

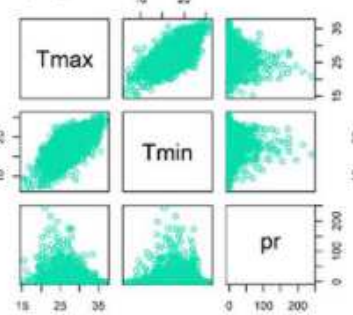

(c2) FUT EQM

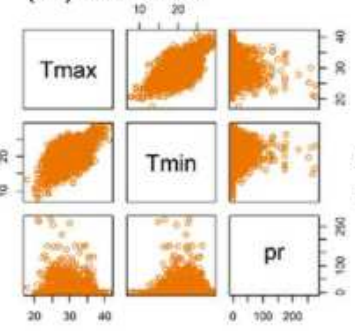

(d1) REF QDM

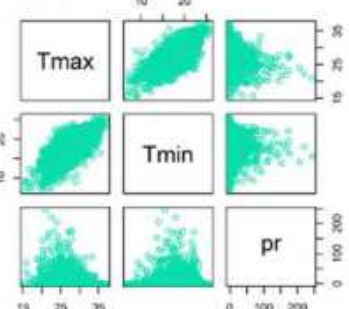

(d2) FUT QDM

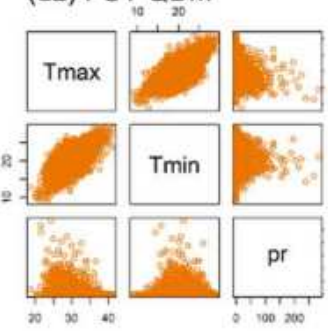

(e1) REF MBCn

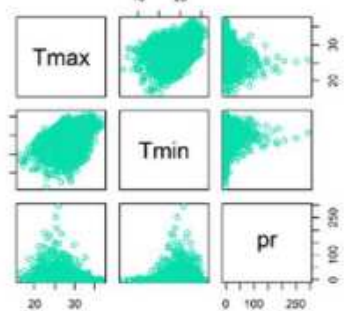

(e2) FUT MBCn

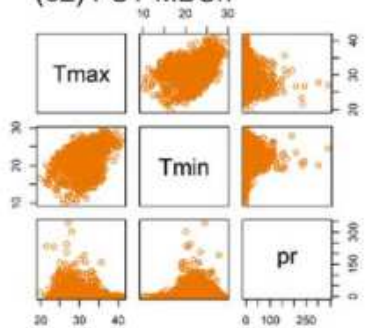

\section{Figure 2}

Illustrative example of the correlation matrices among daily Tmax, Tmin, and precipitation (pr) during JJAS from (a) OBS, (b) RAW, and (c-f) BC products using VAPT, EQM, QDM and MBCn for (1) REF and (2) FUT for a randomly select grid in CCSM4WRF05-REF. 
(a) Chungju Dam basin

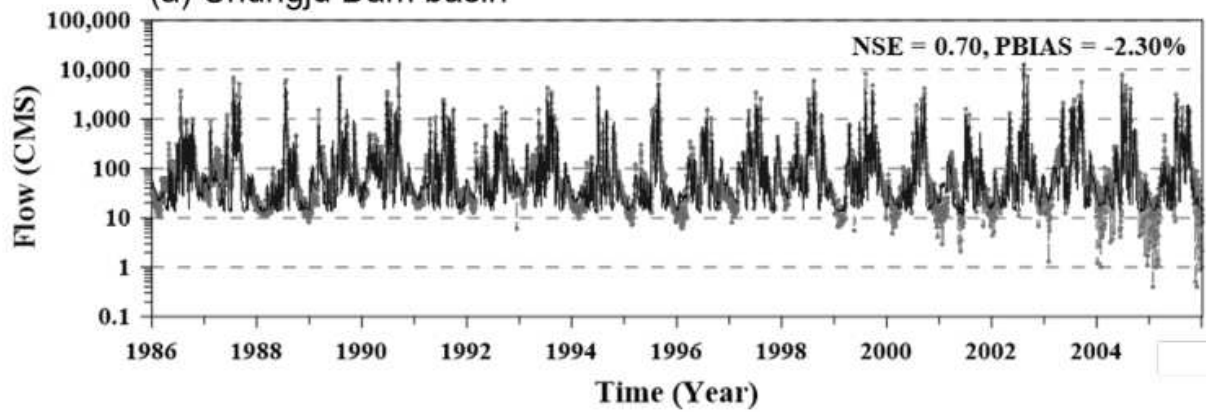

(b) Andong Dam basin

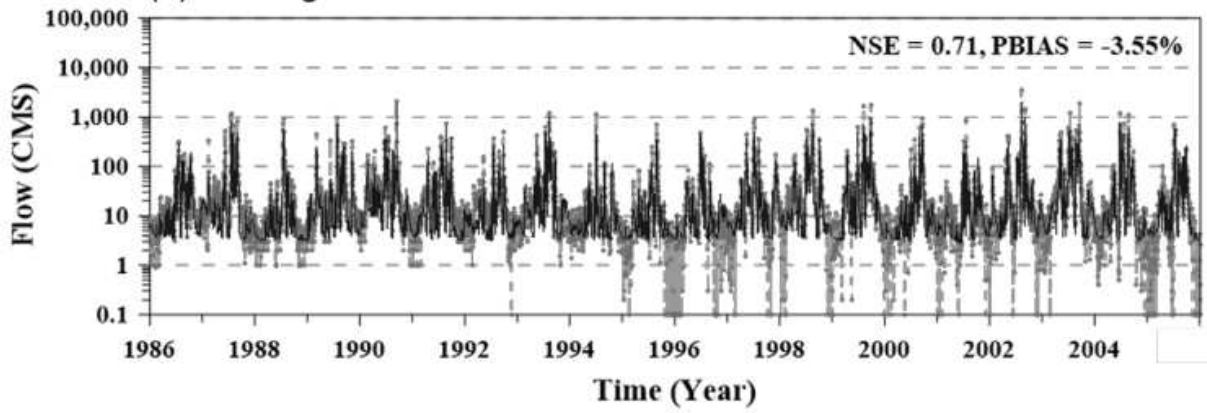

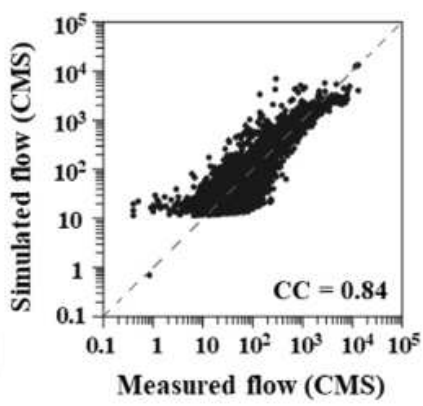

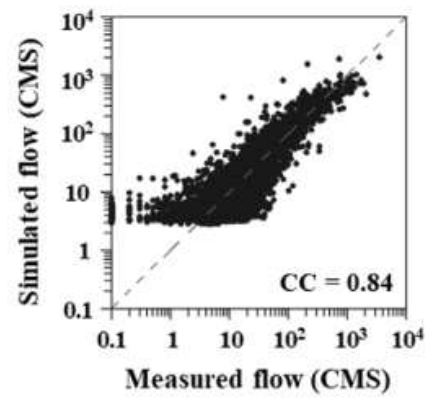

Figure 3

(left column) The daily time series of measured inflow and simulated streamflow in observational run; and (right column) the scatter plot of daily measured inflow (x-axis) versus observational run simulated streamflow (on the y-axis) in the (a) Chungju dam basin and (b) Andong dam basin (unit: CMS). 
pr

$\begin{array}{ll}\text { (a) GCM } & \text { (b) WRF20 }\end{array}$

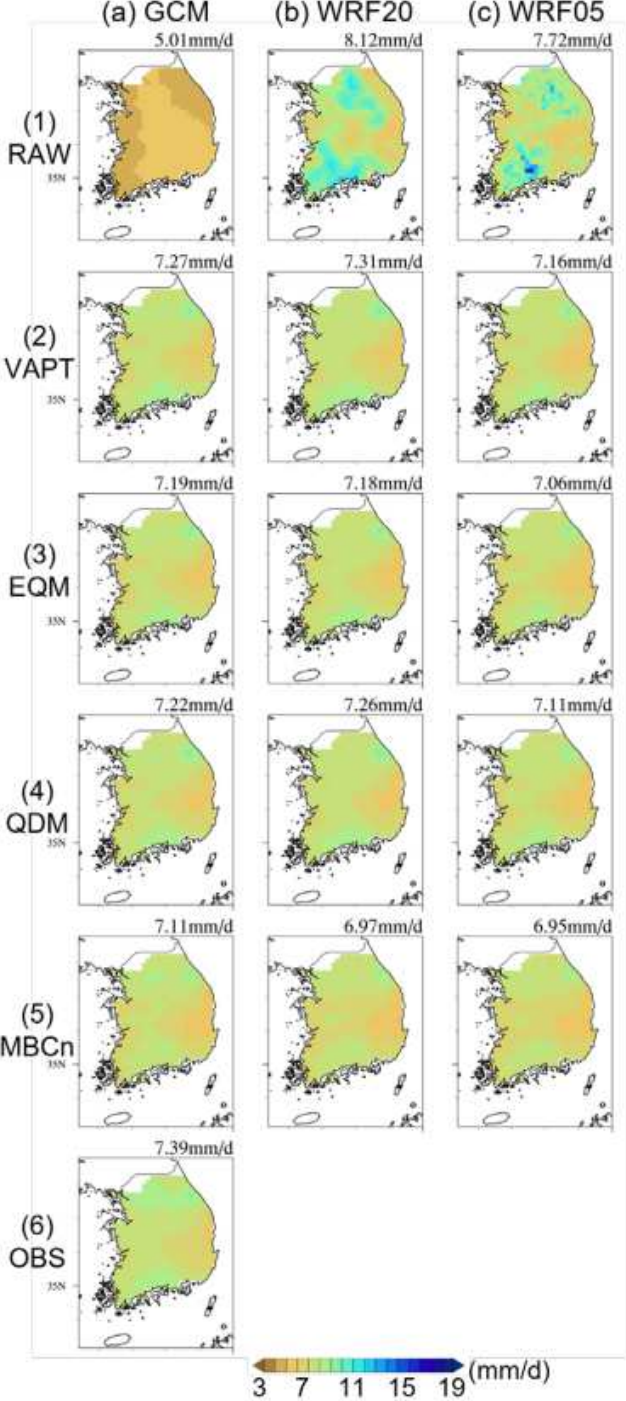

Tmax

$\begin{array}{ll}\text { (a) GCM } & \text { (b) WRF20 }\end{array}$
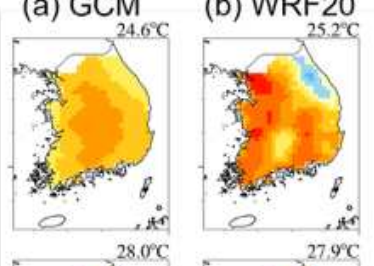

(c) WRF05

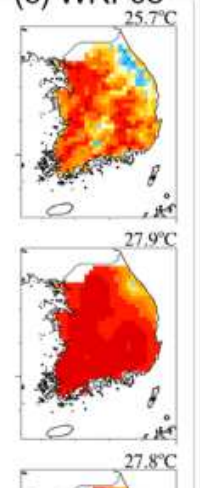

(a) GCM

(b) WRF20

(c) WRF05
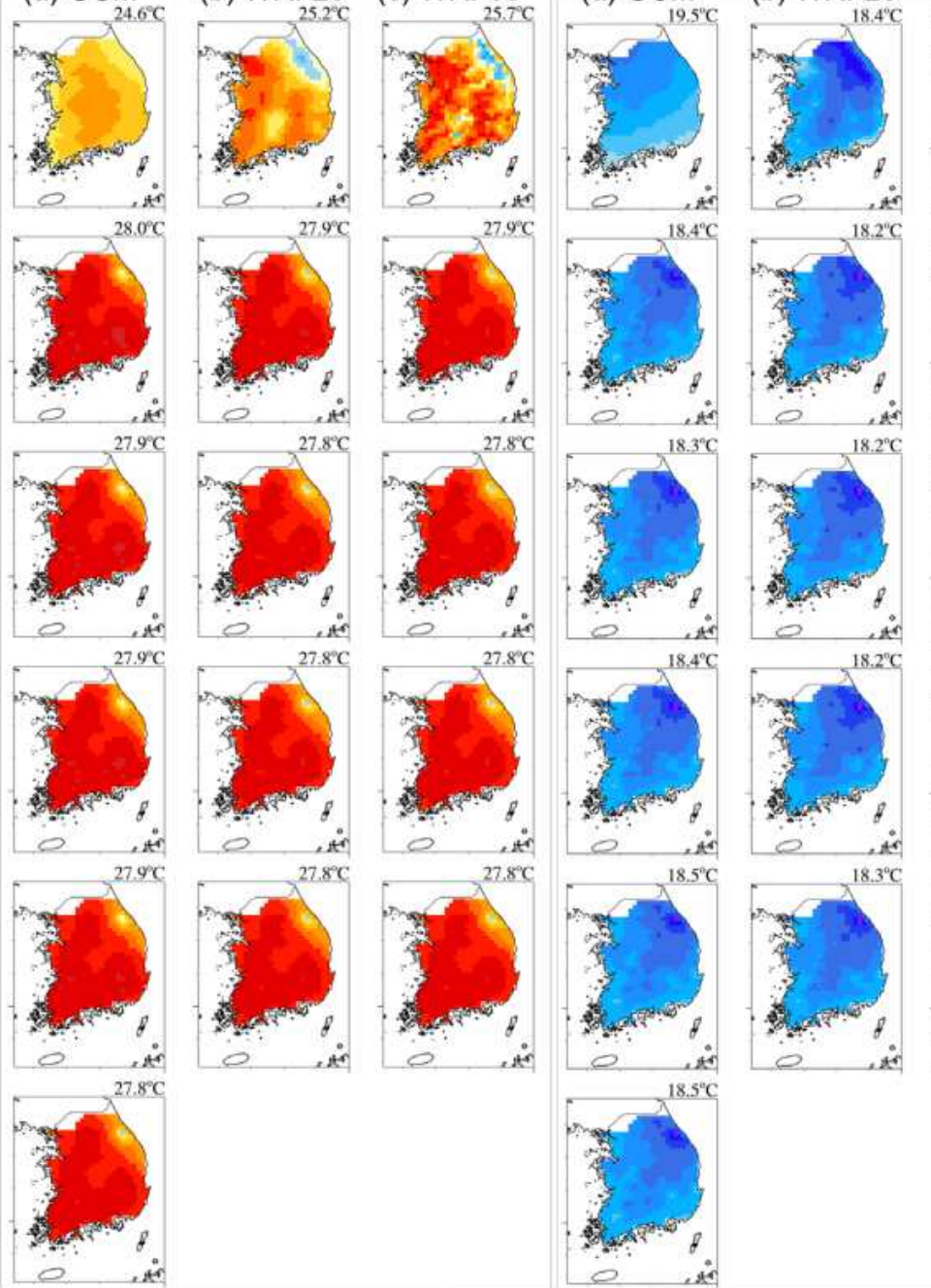
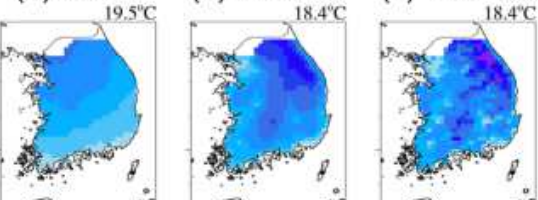

$18.4^{\circ} \mathrm{C}$
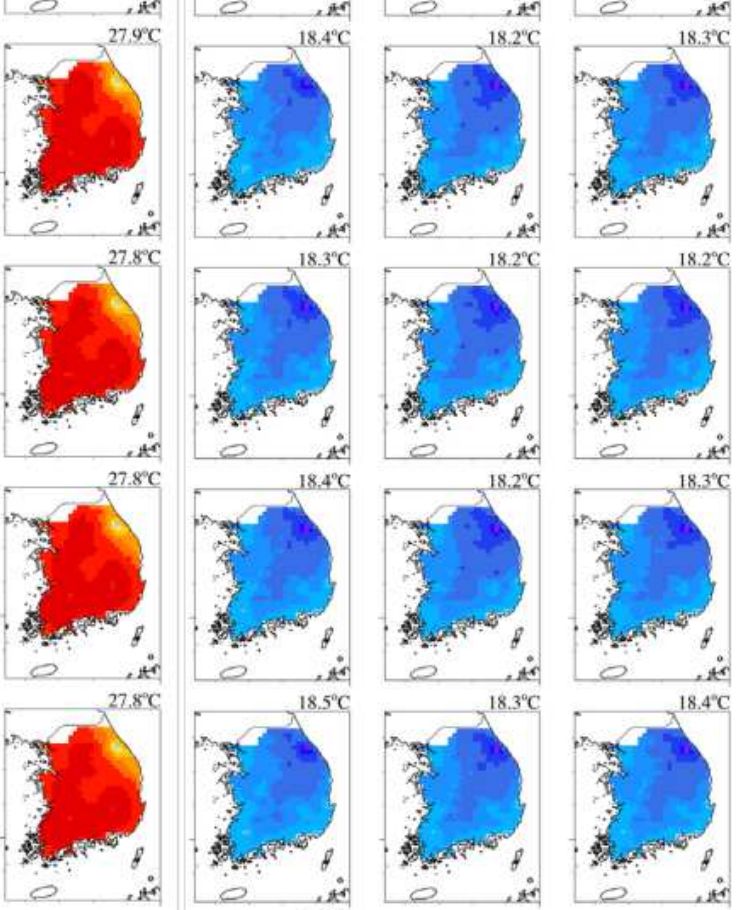

\section{Figure 4}

Spatial maps of climatological mean precipitation (pr), Tmax, and Tmin in JJAS from (a) ENSGCM-REF, (b) ENSWRF20-REF, and (c) ENSWRF05-REF of (1) RAW and its BC products using (2) VAPT, (3) EQM, (4) $\mathrm{QDM}$, and (5) MBCn. (6) is the OBS used as the reference for BC. The value at the top right of each subfigure is the spatial-average value over South Korea land. 
(a) GCM

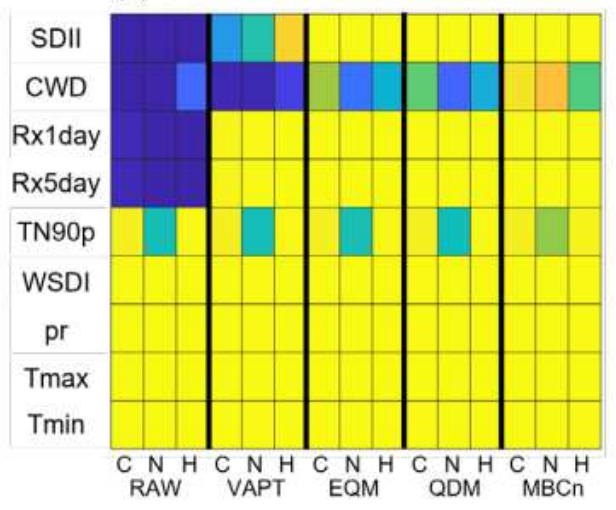

(b) WRF20

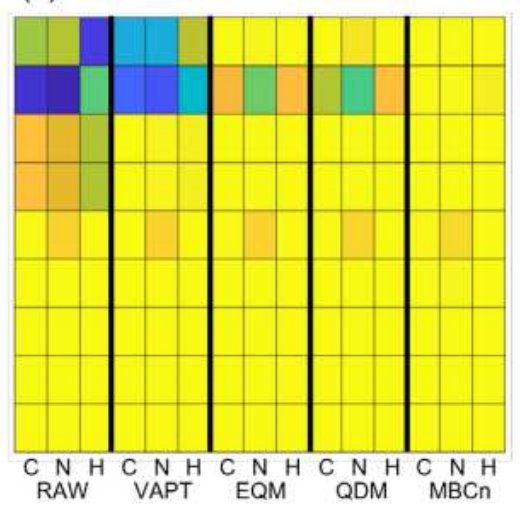

(c) WRF05

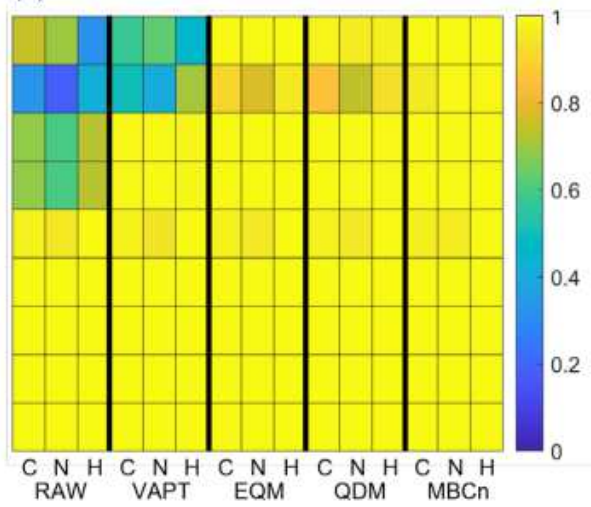

\section{Figure 5}

Plot showing the proportion of grid points passing local K-S diagnostic tests for each ETTCDI index (row 1-6) and JJAS mean precipitation (pr), Tmax, and Tmin (row 7-9) during REF for (a) GCM; (b) WRF20; and (c) WRF05. The letter "C" stands for result from "CCSM4", "N" for "NorESM", "H" for "HadGEM2".

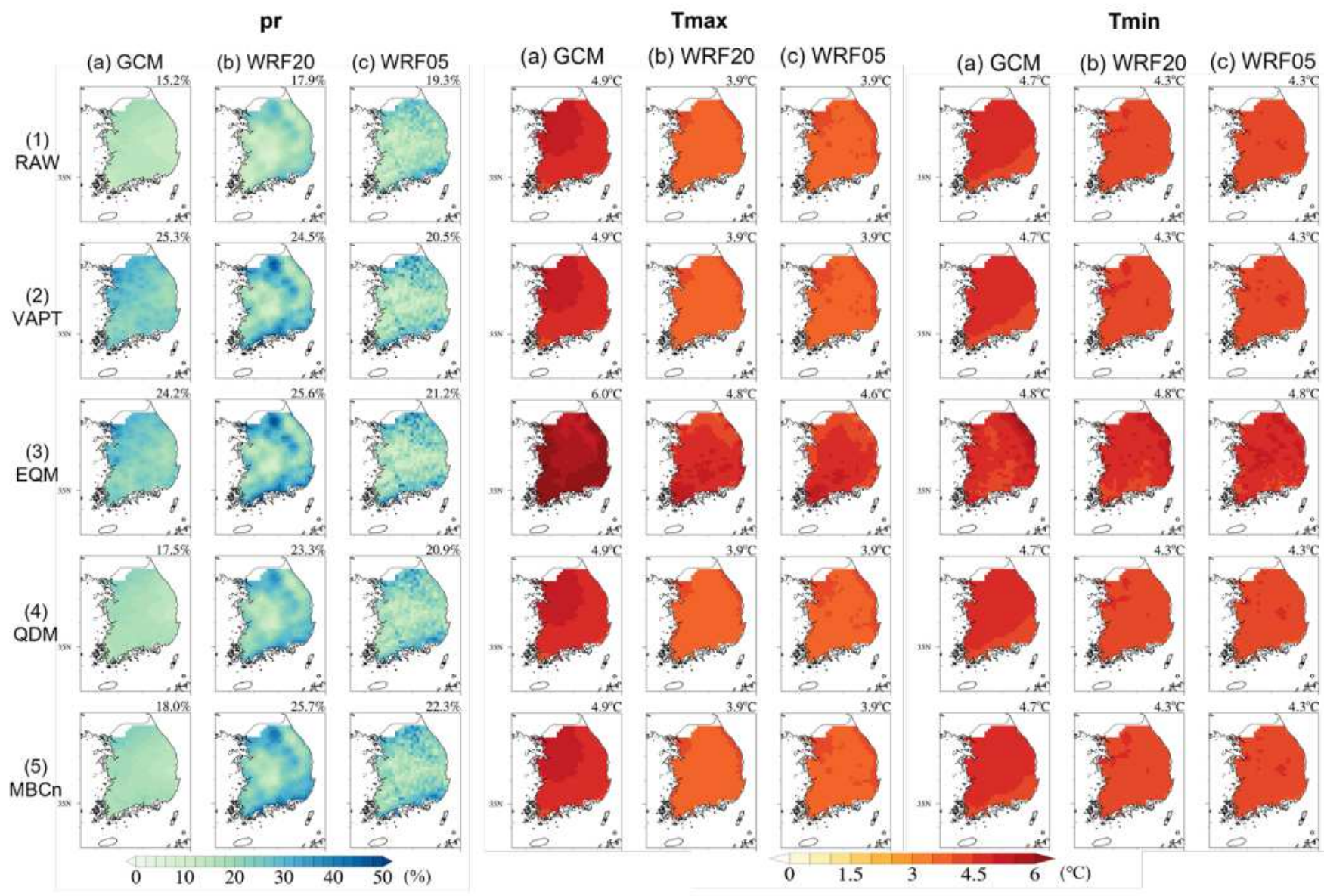

\section{Figure 6}

Spatial maps of the relative change (FUT vs. REF, unit: \%) of climatological mean pr, Tmax, and Tmin in JJAS from (a) ENSGCM, (b) ENSWRF20, and (c) ENSWRF05 of (1) RAW and its BC products using (2) 
VAPT, (3) EQM, (4) QDM, and (5) MBCn. The value at the top right of each sub-figure is the spatialaverage value over South Korea land.

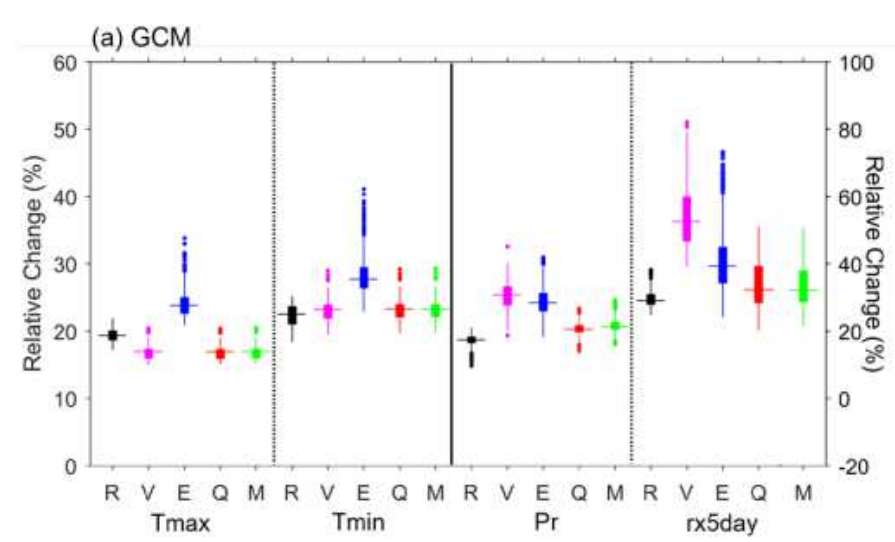

(c) WRF05

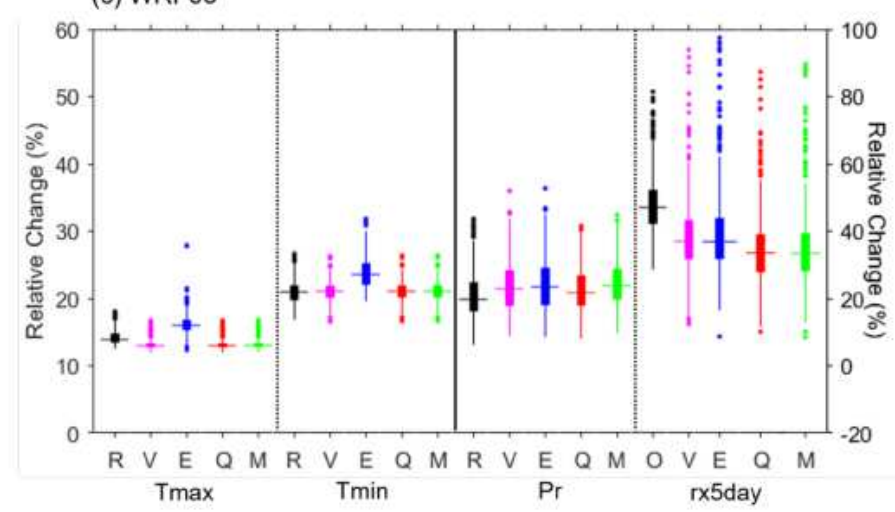

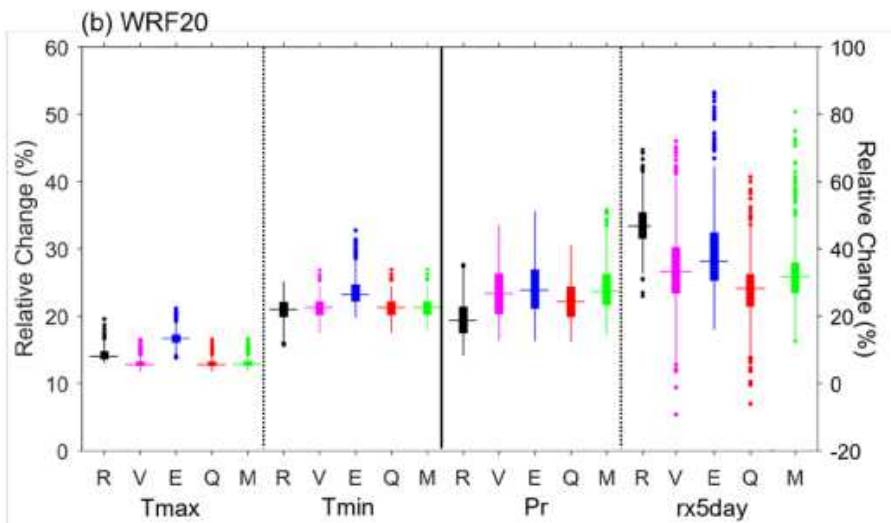

Figure 7

Boxplots of the relative change (FUT vs. REF, unit: \%) in wet season mean Tmax \& mean Tmin (left yaxis), and wet season mean Pr and rx5day (right y-axis) at each grid cell over the South Korea domain (land only) from (a) ENSGCM, (b) ENSWRF20, and (c) ENSWRF05. "R", "V", "E”, “Q”, and "M" stand for RAW, VAPT, EQM, QDM and MBCn respectively. The median change over the domain is given by the central line within each box. 
(1) HRB

(a) CCSM4

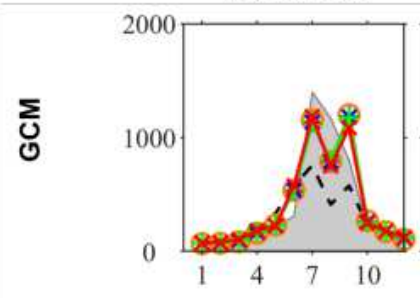

(b) NorESM
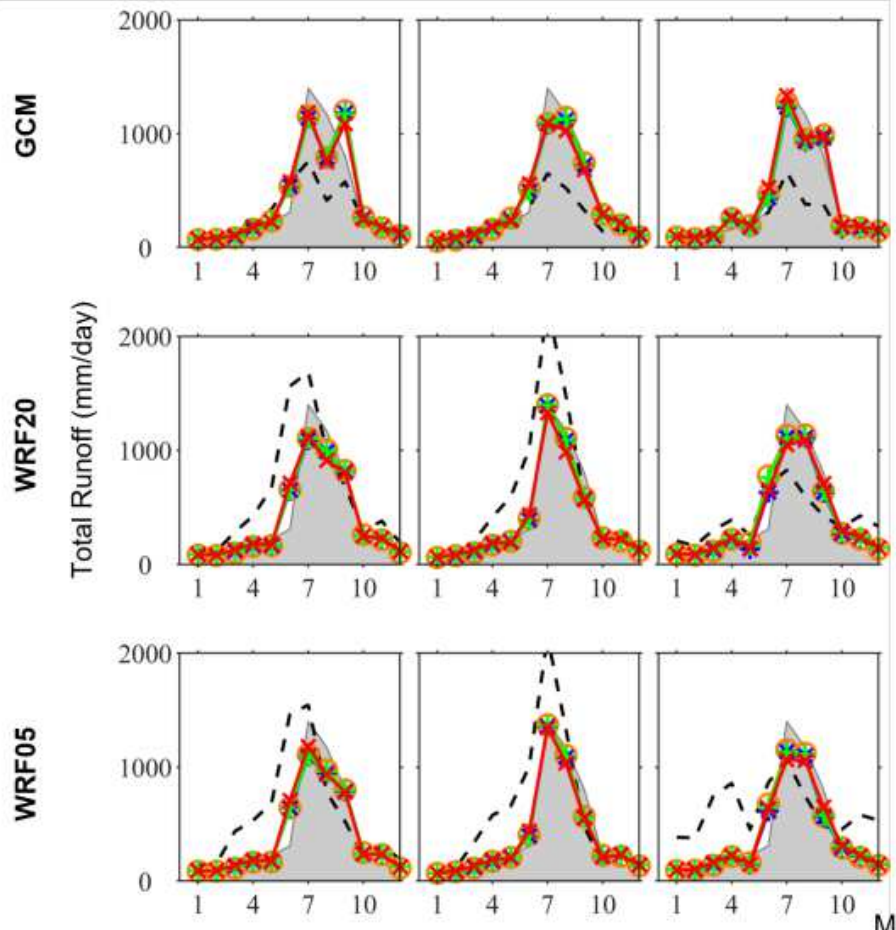

(2) NRB

(a) CCSM4

(b) NorESM

(c) HadGEM2
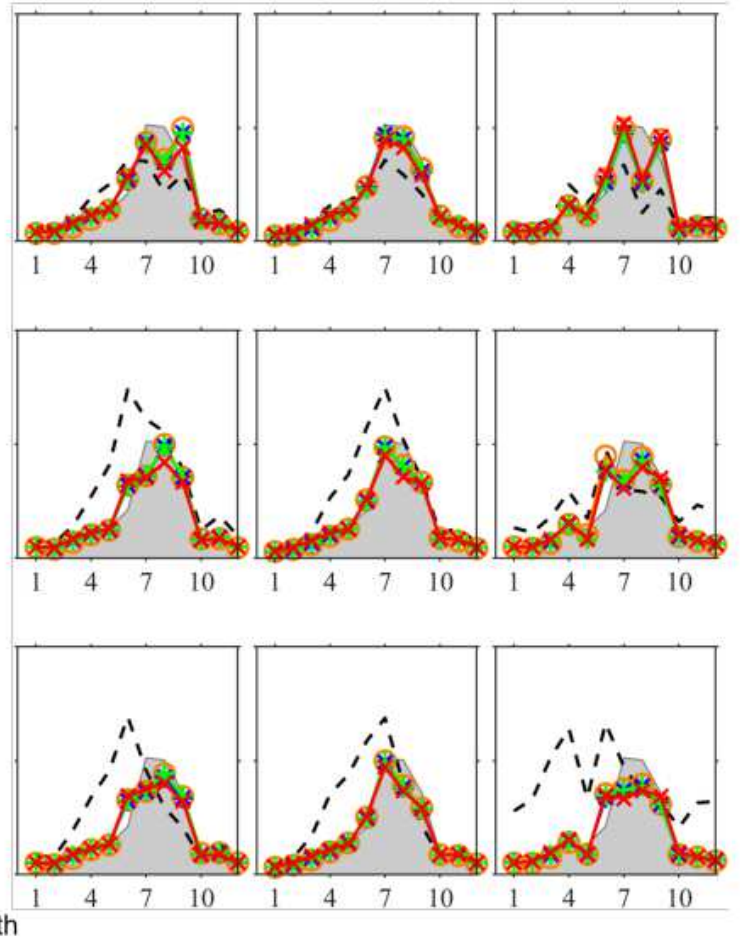

*-EQM $+\mathrm{QDM} \longrightarrow \mathrm{MBCn}$

\section{Figure 8}

Annual cycle of the climatological monthly mean total runoff during REF over (1) HRB and (2) NRB. The lines are from hydrological simulations driven by (a) CCSM4, (b) NorESM, and (c) HadGEM2 in GCM (first row), WRF20 (second row), and WRF05 (third row). The shading is obtained from the hydrological simulation driven by OBS. The total runoff is obtained by adding all the streamflow values of HM grids within the basin. 
(a) Wet season mean

(b) AMDS
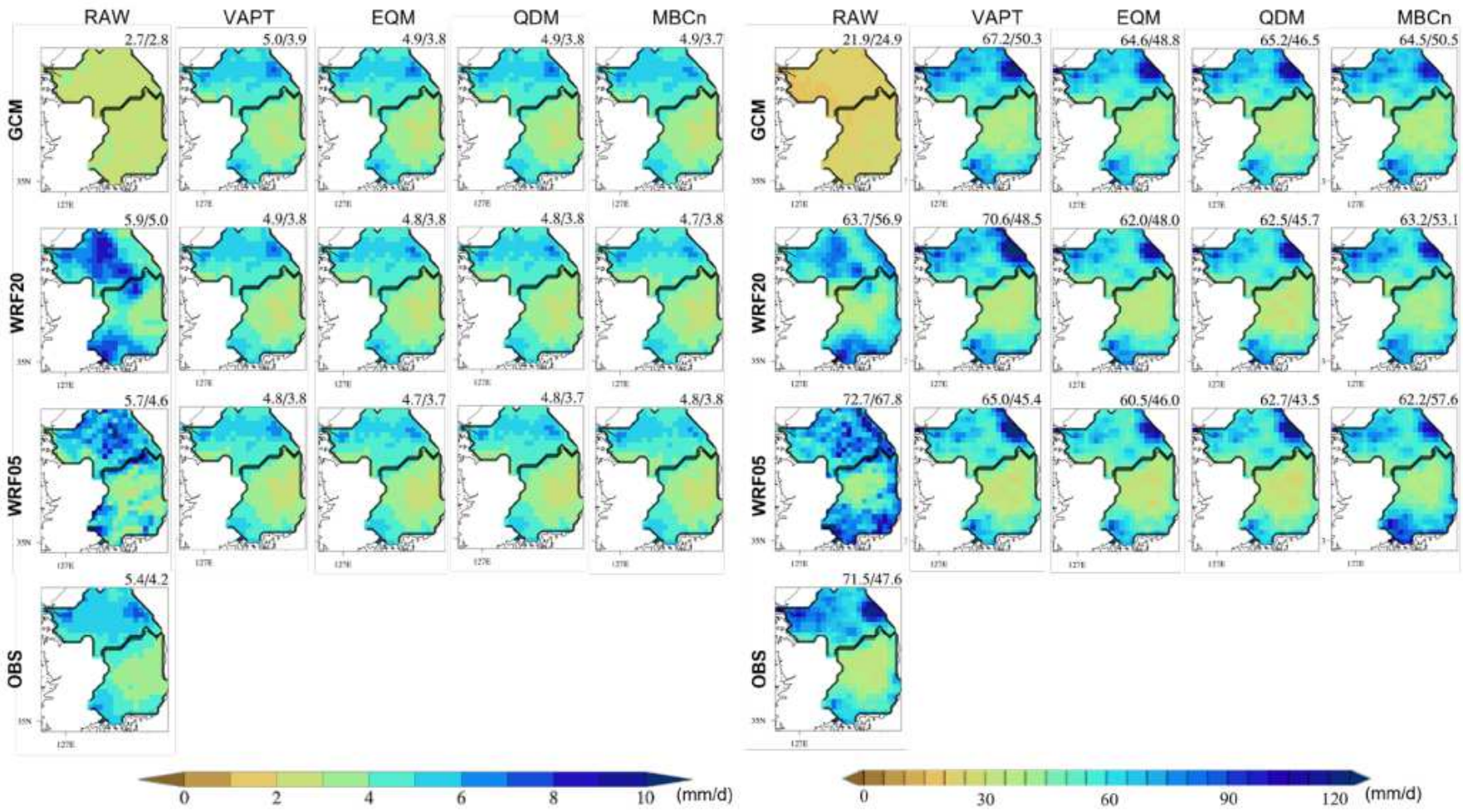

\section{Figure 9}

Spatial pattern over HRB and NRB of the 30-year mean runoff of (a) wet season mean (JJAS) and (b) the high flow represented by the Annual Maximum daily streamflow (AMDS) in ENSGCM (first row), ENSWRF20 (second row), and ENSWRF05 (third row) for hydrological projections using different BC methods and RAW. The fourth row is from OBS run. The value on the top-right corner is the spatialaverage runoff over HRB/NRB. The unit is $\mathrm{mm} /$ day. 
(a) $\mathrm{CCSM} 4_{\mathrm{RAW}}$
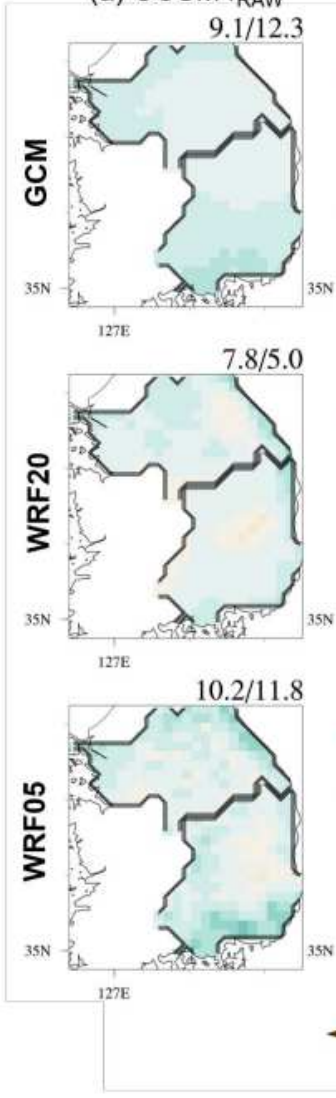

(b) NorESM RAW
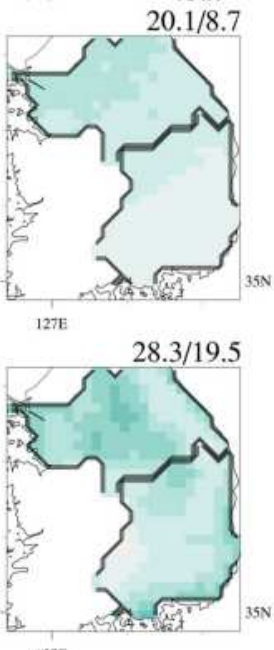

(c) HadGEM2 $2_{\text {RAW }}$
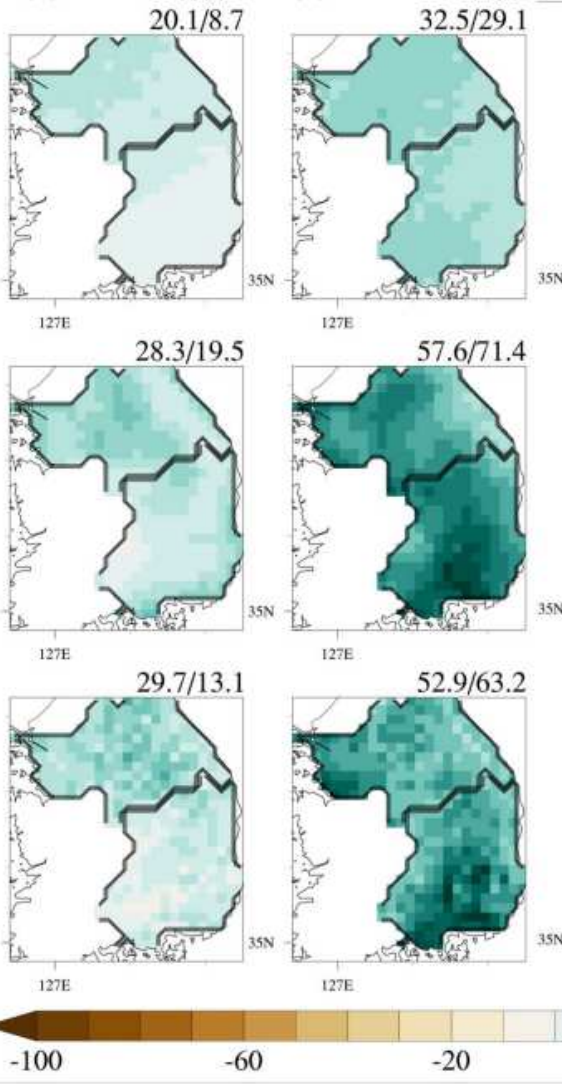

(d) $\mathrm{CCSM} 4_{\text {ENSBC }}$
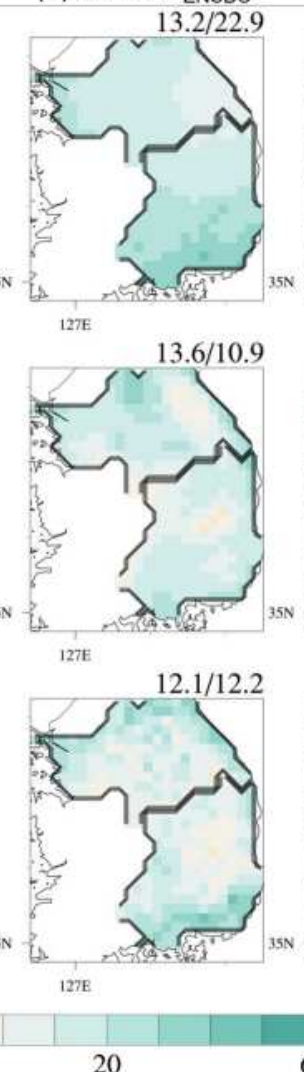

(e) NorESM ENSBC $_{\text {. }}$

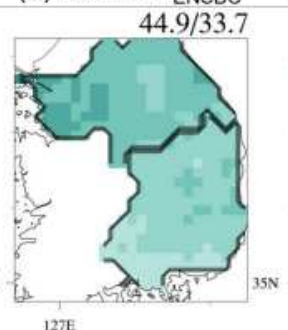

(f) HadGEM2 $2_{\text {ENSBC }}$
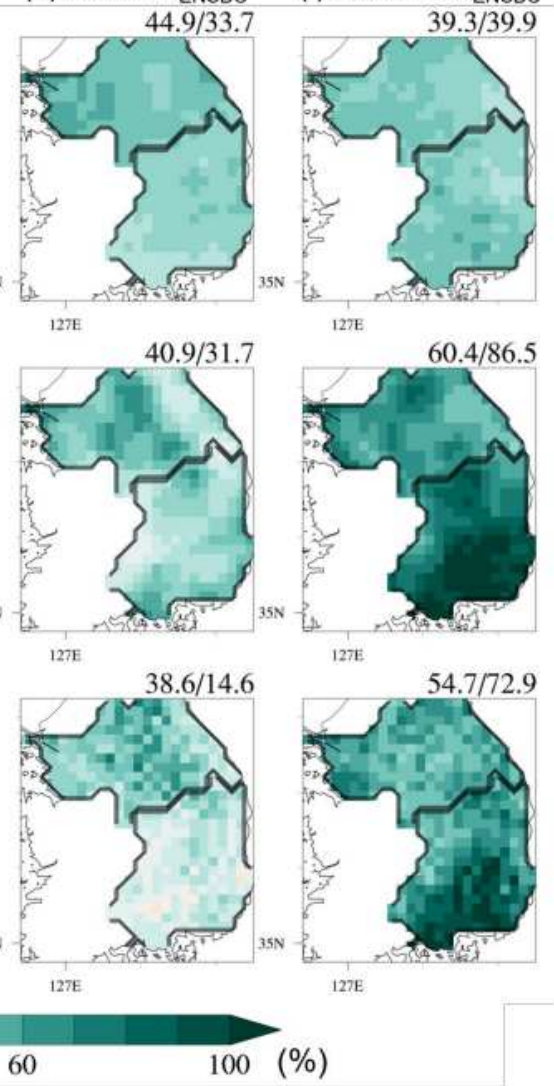

Figure 10

Spatial pattern of the relative change (\%, FUT vs. REF) of simulated runoff during wet season over HRB and NRB from $(a, e)$ CCSM, $(b, f)$ NorESM, $(c, g)$ HadGEM2. (a-d) is from RAW and (e-h) the ensemble mean of those corrected by VAPT, EQM, QDM, and MBCn. The value on the top-right corner is the spatialaverage runoff over HRB/NRB. 
(a) AMDS- HRB

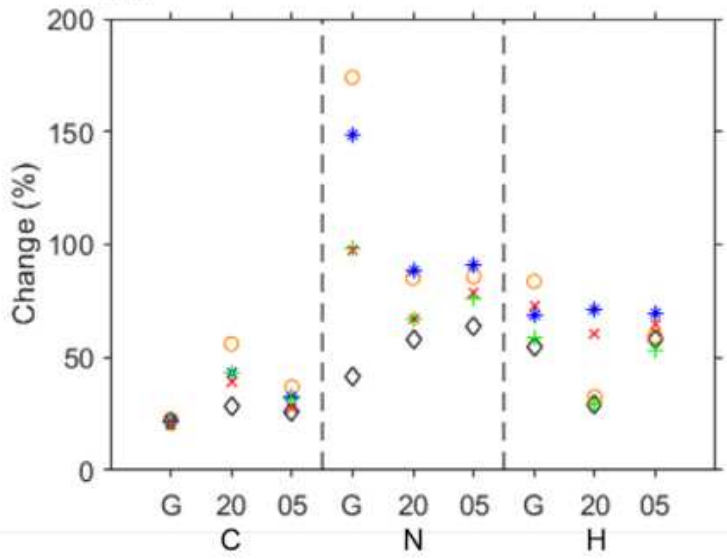

(c) AMDS - NRB

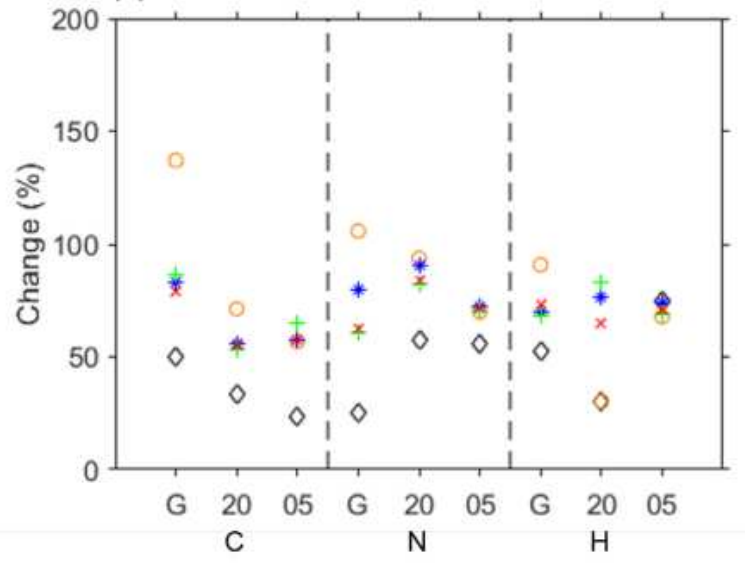

(b) Q95 - HRB

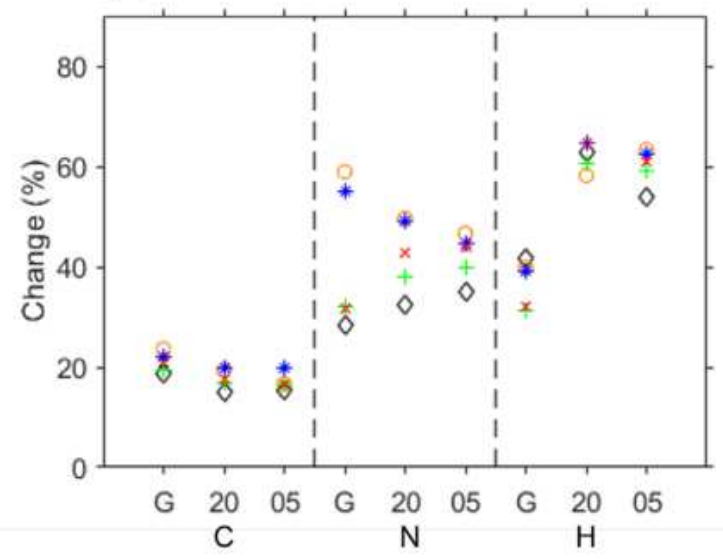

(d) Q95 - NRB

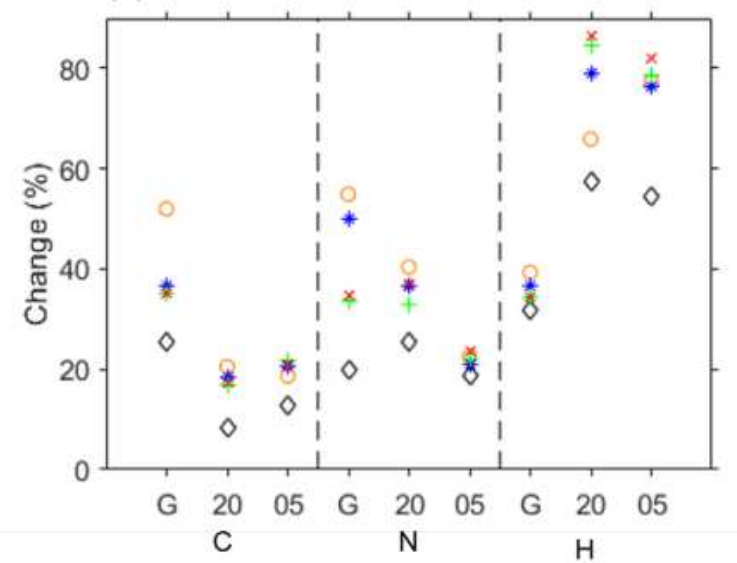

$\triangle$ RAW OVAPT *EQM +QDM $\times$ MBC

\section{Figure 11}

Relative change (FUT vs. REF, unit: \%) of high flow indexes of $(a, c)$ AMDS and $(b, d)$ Q95 over the (a-b) HRB and (c-d) NRB from different hydrological simulations. "C", "N", "H" stand for CMIP5 models of "CCSM4", "NorESM" and "HadGEM2", and "G", "20", "05" stand for the resolution of "GCM", "WRF20", and "WRF05". 